\title{
Corollary Discharge Inhibition and Preservation of Temporal Information in a Sensory Nucleus of Mormyrid Electric Fish
}

\author{
C. C. Bell' and K. Grant ${ }^{2}$ \\ 1The Robert S. Dow Neurological Sciences Institute, Good Samaritan Hospital and Medical Center, Portland, Oregon \\ 97210, and 'Laboratoire de Physiologie Nerveuse, Departement de Neurophysiologie Sensorielle, CNRS, 91190, Gif-sur- \\ Yvette, France
}

Knollenorgan electroreceptors in mormyrid fish are concerned with electrocommunication, i.e., with detecting electric organ discharges (EODs) of other electric fish. But knollenorgan electroreceptors are also activated by the fish's own EOD. Potential interference by such self-stimulation is blocked by an inhibitory corollary discharge in the nucleus of the electrosensory lateral line lobe (NELL), the first central relay of the knollenorgan pathway. This study used intracellular recording and staining to examine the mechanism of the corollary inhibition and the specializations in anatomy and physiology that permit the accurate relaying of temporal information about the EODs of other fish.

Several events are recorded inside primary knollenorgan afferents in addition to a large orthodromic action potential. The additional events include small orthodromic electrotonic epsps, postsynaptic action potentials, and a corollary discharge inhibitory postsynaptic potential (ipsp) associated with the EOD motor command. These additional events are also recorded in NELL cells and almost certainly originate there. Electrical coupling between afferents and cells makes it possible to observe the events inside primary afferents. The corollary discharge ipsp in the cell is associated with a conductance increase and inverts rapidly when recorded with chloride-containing electrodes, supporting a hypothesis of GABA mediation. The ipsp lasts longer in cells than in afferents.

Each electrotonic excitatory postsynaptic potential (epsp) is probably caused by a single primary afferent, and any one of several epsps in a given cell seems capable of eliciting a postsynaptic spike in that cell. The epsps follow stimulation rates as high as $500 / \mathrm{sec}$ with minimal variability. No lateral inhibition is observed in NELL. These and other properties indicate that the knollenorgan pathway is specialized for temporal information rather than spatial or intensity information.

Received June 6, 1988; revised Aug. 15, 1988; accepted Aug. 25, 1988

Funding for this project was provided by a grant (to C.C.B.) from the National Institutes of Health, and by a U.S.-France Cooperative Grant (to C.C.B. and K.G.) from the National Science Foundation and the Centre National de la Recherche Scientifique. We would like to thank Andrea Frost for her extensive work on the figures.

Correspondence should be addressed to Curtis Bell, Ph.D., The Robert S. Dow Neurological Sciences Institute, Good Samaritan Hospital and Medical Center, 1120 N.W. 20th Ave., Portland, OR 97209.

Copyright (C) 1989 Society for Neuroscience $0270-6474 / 89 / 031029-16 \$ 02.00 / 0$
The purpose of this paper is to provide more nearly complete descriptions of (1) the dramatic corollary discharge inhibition that occurs in the mormyrid electric fish at the first central relay of the electrocommunication pathway, and (2) the specialized features of this pathway that permit the accurate relaying of temporal information.

Weakly electric fish, such as the mormyrids, use their active electrosensory systems for electrocommunication and for active electrolocation. In electrocommunication, the fish emit electric organ discharges (EODs) and detect the EODs of other fish during such social behaviors as establishing territories and finding mates. In active electrolocation, the fish detect nearby objects by the distortions that such objects cause in the electric field of their own self-generated EOD.

Electric fish of the family Mormyridae possess 3 types of electroreceptors: knollenorgans, mormyromasts, and ampullary organs (Bennett, 1965; Szabo and Fessard, 1974). Knollenorgans have their major role in electrocommunication, whereas mormyromasts have their major role in active electrolocation. Ampullary organs have their role in the sensing of low-frequency electrical signals that are generated by a variety of biological and nonbiological sources. Afferents from the 3 types of electroreceptors project to different parts of the electrosensory lateral line lobe (ELL; Fig. $1 A$ ) in the medulla. Knollenorgan afferents terminate in the nucleus of the electrosensory lateral line lobe (NELL; Figs. 1, $A, B$; Enger et al., 1976a, b), whereas morymyromast and ampullary afferents terminate in the cortex of the same structure (Bell and Russell, 1976, 1978; Szabo et al., 1979; Bell, 1986). This study is concerned only with the NELL, the first-order knollenorgan relay.

The NELL has only 3 major neuronal elements: knollenorgan afferent fibers, fibers from the sublemniscal nucleus anterior to ELL (Bell et al., 1981), and the cells of NELL (Fig. 5A). Knollenorgan primary afferents terminate on NELL cells with large club endings. These endings are morphologically mixed, with both electrical and chemical synaptic structures (Szabo et al., 1983; Mugnaini and Maler, 1987b). Fihers from the sublemniscal nucleus are thin and terminate with numerous small boutons on the somas and initial segments of the NELL cells (Bell et al., 1981; Szabo et al., 1983; Mugnaini and Maler, 1987b). The boutons have the morphology of chemical synapses and stain positively for both glutamic acid decarboxylase (GAD) and GABA (Denizot et al., 1987; Mugnaini and Maler, 1987b). The cells of NELL are round and adendritic, with axons that project to the anterior exterolateral nucleus of the mesencephalon (Enger et al., 1976b; Bell et al., 1981; Szabo et al., 1983). 
There is no evidence for interneurons in NELL or for recurrent collaterals of NELL cells.

The GAD-containing boutons that surround the NFI I, cells are almost certainly responsible for the profound inhibition that occurs in NELL and that is elicited by a corollary discharge of the motor command that drives the electric organ. Transmission through the nucleus appears to be completely blocked for 1-2 msec following each EOD motor command, with a rapid recovery of transmission following the inhibition (Bennett and Steinbach, 1969; Zipser and Bennett, 1976; Russell and Bell, 1978; Szabo et al., 1979).

The latency and duration of the corollary discharge inhibition are such that the responses of the fish's own knollenorgan afferents to its own EOD are blocked at this first sensory relay. The self-induced sensory input is thus prevented from affecting the higher centers of the knollenorgan system and interfering with the analysis of the EODs of other fish.

The corollary discharge inhibition has been observed with evoked potentials in the anterior exterolateral nucleus, which is the mesencephalic target of axons from NELL (Bennett and Steinbach, 1969; Russell and Bell, 1978; Szabo et al., 1979), and in single-unit studies within ELL in recordings from what were probably the axons of NELL cells (see Discussion) (Zipser and Bennett, 1976). However, the corollary discharge inhibition has not yet been examined at the intracellular site where it occurs and its cellular mechanisms have, therefore, not been explored. Such examination of the inhibition with intracellular recordings from NELL cells was one major goal of the present study.

The higher knollenorgan centers are probably responsible for analyzing the temporal features of the EODs of other fish, including both the duration of individual EODs and the pattern of inter-EOD intervals (Bell et al., 1974; Kramer, 1974, 1979; Hopkins and Bass, 1981). Analysis by the higher knollenorgan centers requires, however, that the temporal information contained in the sensory signals be well maintained in the pathway from the receptor through the NELL to the mesencephalon. Such preservation of temporal information is made possible by several morphological and physiological features of the knollenorgan pathway, and a second major goal of the present study was to provide a more complete description of these features.

\section{Materials and Methods}

Experiments were performed on 15 mormyrid fish of the species Gnathonemus petersii ranging in length from 14 to $17.5 \mathrm{~cm}$. Surgery was carried out to expose the brain. Following surgery, electrosensory stimuli were delivered to the skin, and recordings were made from the 3 neuronal elements of NELL.

Surgery. Surgery was carried out under anesthesia (MS-222, 1:25,000) and consisted of removing part of the caudal cranium to expose the ELL. The intracranial portion of the posterior lateral line nerve was also exposed in some fish to permit recording from afferent axons in the nerve root. Finally, the ipsilateral anterior exterolateral nucleus of the mesencephalon was exposed to permit the insertion of a stimulating electrode for antidromic activation of the axons of NELL cells. At the end of the surgery, $0.075 \mathrm{mg}$ turbocurarine chloride in isotonic saline was injected intramuscularly. Anesthesia was then stopped by passing fresh, aerated water through the mouth and over the gills at a flow rate of $30 \mathrm{ml} / \mathrm{min}$. The above curare dose was repeated once or twice over $30 \mathrm{hr}$ to maintain the curarized condition.

Stimulation. Brief electrical stimuli of $200 \mu \mathrm{sec}$ in duration were used to activate knollenorgan electroreceptors. The stimuli were usually given at various delays with respect to the command signal but were also given independently of the command signal. Stimuli were given in 2 ways: (1) The whole fish was stimulated by passing current between a silver ball electrode passed into the stomach through the mouth and a silver wire running along the wall of the tank parallel to the fish, and (2) local skin areas and individual knollenorgan receptors were stimulated with a pair of silver wires insulated except at the tips and separated by 1 $\mathrm{mm}$. Individual electroreceptors are easily observed with the operating microscope.

Antidromic activation of NELL cells was obtained by stimulating the ipsilateral anterior exterolateral nucleus, using a pair of sharpened tungsten electrodes that were insulated except at the tip.

Recording. Curare blocks synaptic transmission between electromotoneuron axons and electrocytes, thus preventing an EOD. However, the synchronized volley in the electromotoneurons, which would normally elicit an EOD in an all-or-none manner, continues to be generated spontaneously in the curarized fish at rates of $2-5 / \mathrm{sec}$ (Fig. $4 B$, bottom trace). In the normal noncurarized fish, the EOD follows the third and last peak of this motor command or "command signal" at a fixed delay of about $1.5 \mathrm{msec}$. This command signal was recorded outside the fish between a chlorided, silver disk placed against the skin over the clcctric organ and a chlorided, silver wire in the bath a few centimeters away.

Field potentials associated with the EOD motor command and with electrosensory stimuli served to locate the NELL for subsequent intracellular recording. Field potentials were recorded with $3 \mathrm{~m} \mathrm{NaCl}$-filled micropipettes that had resistances of 2-5 M . The indifferent electrode was a chlorided, silver wire placed on the surface of the brain.

Most intracellular recordings were obtained from NELL itself, but some were also obtained from the nerve root of the posterior lateral line nerve. The intracellular recordings were made with glass micropipettes filled with either $3 \mathrm{~m} \mathrm{KCl,} 4$ м KAc, $1 \mathrm{~m} \mathrm{LiCl}$ containing $10 \%$ Lucifer yellow, or $0.5 \mathrm{M} \mathrm{KCl}$ in $0.1 \mathrm{~m}$ Tris ( $\mathrm{pH} 7.2$ ) containing $5-10 \%$ HRP (Sigma Type VI). Tip diameters were less than $0.5 \mu \mathrm{m}$, and resistances ranged from 25 to $160 \mathrm{M} \Omega$, depending on the filling solution. Membrane potentials for the fibers and cells that were studied here ranged from 20 to $70 \mathrm{mV}$. Recorded neurons were labeled by intracellular iontophoresis of Lucifer yellow (electrode tip negative, 1-3 nA for $1.5-4 \mathrm{~min}$ ) or HRP (electrode tip positive, $2-10 \mathrm{nA}$ for 4 to $10 \mathrm{~min}$ ).

Identification. In addition to knollenorgan afferents, mormyromast and ampullary afferents were also recorded in the nerve root and in the brain outside the borders of NELL. Knollenorgan afferents are readily distinguished from the other 2 types of electrosensory afferents, however, by a variety of physiological measures including threshold, latency shift with changes in stimulus intensity, spontaneous activity, and responsiveness to long-duration stimuli (Bennett, 1965; Szabo and Fessard, 1974). The 3 types of afferents are also distinct in the intracellularly recorded corollary discharge effects: an inhibitory postsynaptic potential (ipsp) is observed inside knollenorgan afferents (see below), an excitatory postsynaptic potential (epsp) is observed inside mormyromast afferents (Slesinger and Bell, 1985), and no corollary discharge effect is observed inside ampullary afferents (C. C. Bell, unpublished observations).

Histology. At least $2 \mathrm{hr}$ were allowed to pass between the last intracellular injection of HRP or Lucifer yellow and perfusion of the fish. For perfusion, the fish was reanesthetized and perfused through the heart with a washing solution of teleost Ringer's followed by fixative. A $4 \%$ solution of formaldehyde in $0.1 \mathrm{M}$ phosphate buffer ( $\mathrm{pH} 7.2$ ) was used for the fixative if Lucifer yellow had been injected intracellularly and a $4 \%$ solution of glutaraldehyde in $0.1 \mathrm{~m}$ phosphate buffer was used for the fixative if HRP had been injected. The brain was sectioned at 60 $\mu \mathrm{m}$ on a Vibratome. Following Lucifer yellow injections, the sections were dehydrated, cleared in methyl salicylate, and mounted in Eukitt (Kindler) mounting medium for viewing with a fluorescence microscope. Following HRP injections, the sections were processed with a modified Hanker Yates procedure (Bell et al., 1981), counterstained with Richardson's stain, dehydrated, cleared in xylene, and mounted in Eukitt. Reconstructions of both the Lucifer ycllow- and the HRPlabeled elements were done with the aid of a camera lucida.

\section{Results}

The primary knollenorgan afferents and the cells of NELL were examined both physiologically and morphologically with intracellular recording and staining. The fibers responsible for the corollary inhibition were probably recorded physiologically but were not successfully labeled by intracellular staining.

\section{Morphology}

\section{Morphology of knollenorgan afferents}

All 15 of the knollenorgan afferents that were successfully labeled were found to terminate in NELL, and no branches were 

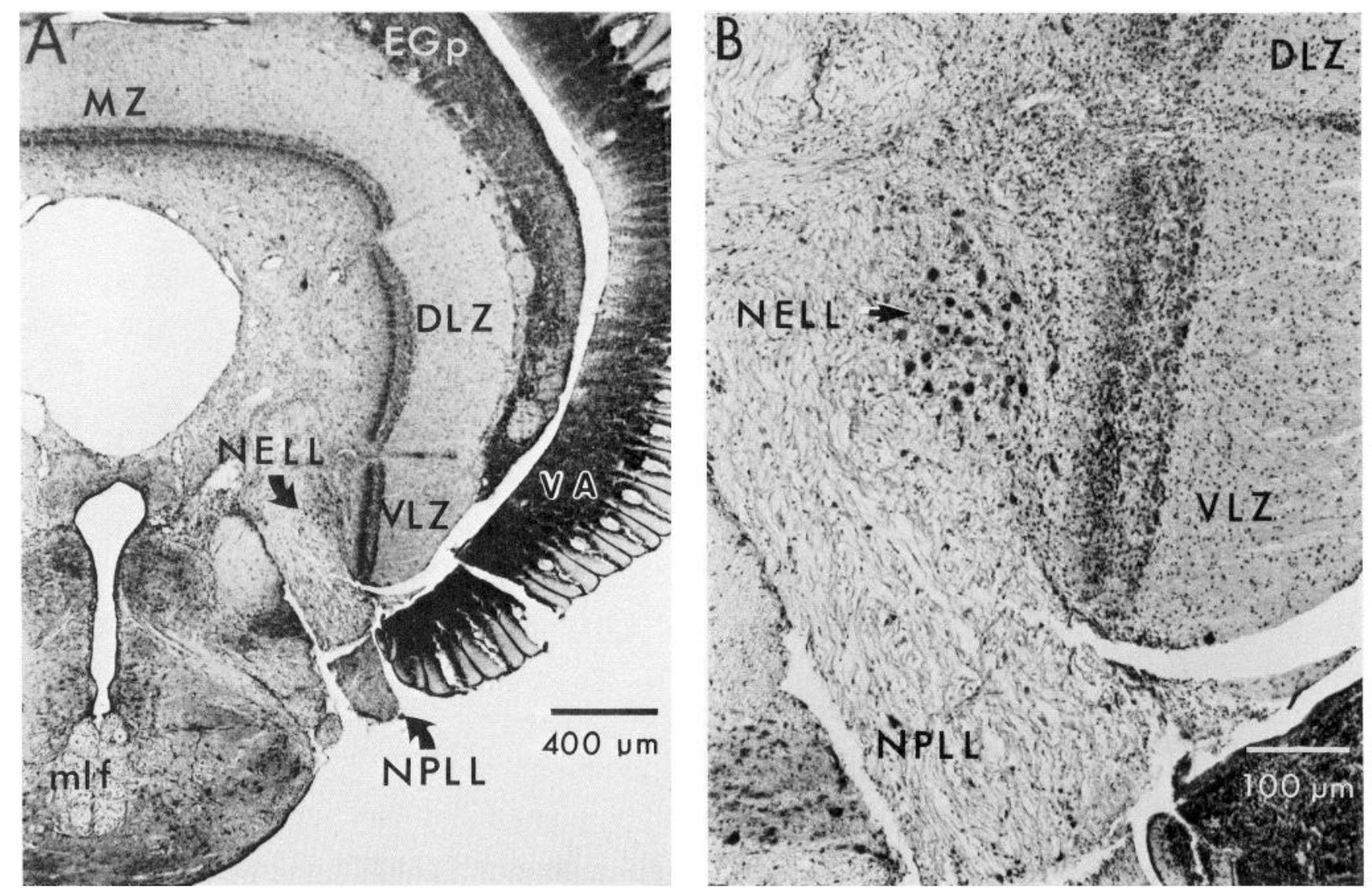

Figure 1. Transverse section through the medulla of the mormyrid Gnathonemus petersii stained with a Nissl stain (Richardson's). A, Low-power photograph showing the brain stem and the ELL. $B$, Higher-power photograph showing the NELL. DLZ, dorsolateral zone of ELL cortex; EGp, eminentia granularis posterior; mlf, medial longitudinal fasciculus; $M Z$, medial zone of ELL cortex; $N E L L$, nucleus of the electrosensory lateral line lobe; $N P L L$, posterior lateral line nerve; $V A$, valvula cerebelli; $V L Z$, ventrolateral zone of ELL cortex.

found terminating in the cortex of ELL. This confirms the earlier identification of NELL as the termination site for knollenorgan afferents (Enger et al., 1976a, b). The previously described somatotopy within the nucleus (Bell and Russell, 1978) was also confirmed in that afferents from electroreceptors on the dorsal skin surface were found to terminate in the ventral half of the nucleus, whereas those from the ventral skin surface were found to terminate in the dorsal half of the nucleus. The somatotopy was not fine-grained, however. Rough estimates indicated that the cells contacted by a single afferent could extend over $1 / 4$ to $1 / 3$ of the dorsoventral extent of the nucleus, and over $1 / 6$ to $1 / 4$ of the rostrocaudal extent (Fig. 2).

The labeled afferents were between 7 and $10 \mu \mathrm{m}$ in diameter as they entered the brain via the posterior lateral line nerve root. The first major branches of the afferent usually occurred outside the borders of the nucleus (Fig. 2). The total number of branches inside and outside the nucleus was small, however $(4,9$, and 6 for the afferents shown in Fig. 2, $B, C$, and $D$, respectively) and most of the branches remained large $(1-4 \mu \mathrm{m})$ up to the terminals (Figs. 2, 3). Some labeled afferents, however, had a few fine branches of less than $1 \mu \mathrm{m}$, in addition to the thick branches (Figs. 2C, 3D).

The thick branches terminated on the cells of NELL with large club endings and spoon endings (Figs. 2, 3) as described in previous morphological studies (Bell and Russell, 1978; Szabo et al., 1978, 1983; Mugnaini and Maler, 1987b). The thin branches, when they could be traced to their terminations, ended as small club endings (Fig. 3D). The most common pattern was a single cell receiving only one terminal from a single primary afferent, but single cells could also receive 2,3 , or 4 terminals from a single primary afferent (Figs. 2, 3).

The number of cells contacted by each afferent appeared to be quite small, although this number could not be determined exactly. Terminals were difficult to identify for many fibers. Moreover, some synaptic contacts were probably missed even in well-stained fibers like those in Figure 2. Stained axonal branches sometimes passed quite close to one cell before ending with a terminal swelling on a second cell (arrows in Fig. 2, B, $D$ ), and such associations between afferents and cells might have been en passant synapses, which have been identified in NELL with the electron microscope (Mugnaini and Maler, 1987b). If one considers only the cells with clear terminals upon them, then the number of cells contacted synaptically by the welllabeled fibers of Figure 2 were 3, 6, and 7 for Figures 2, $B, C$, and $D$, respectively. The number of possible en passant contacts seemed few, however, suggesting that the actual number of cells contacted was only $1-4$ cells greater than the above counts.

\section{Cells of NELL}

Three NELL cells were labeled, all with Lucifer yellow (Fig. $3 E$ ). No dendritic processes were seen, confirming previous morphological studies of NELL (Szabo et al., 1978, 1983; Bell et al., 1981; Mugnaini and Maler, 1987b). The axon of one labeled cell could be followed: it passed dorsally, medially, and ante- 


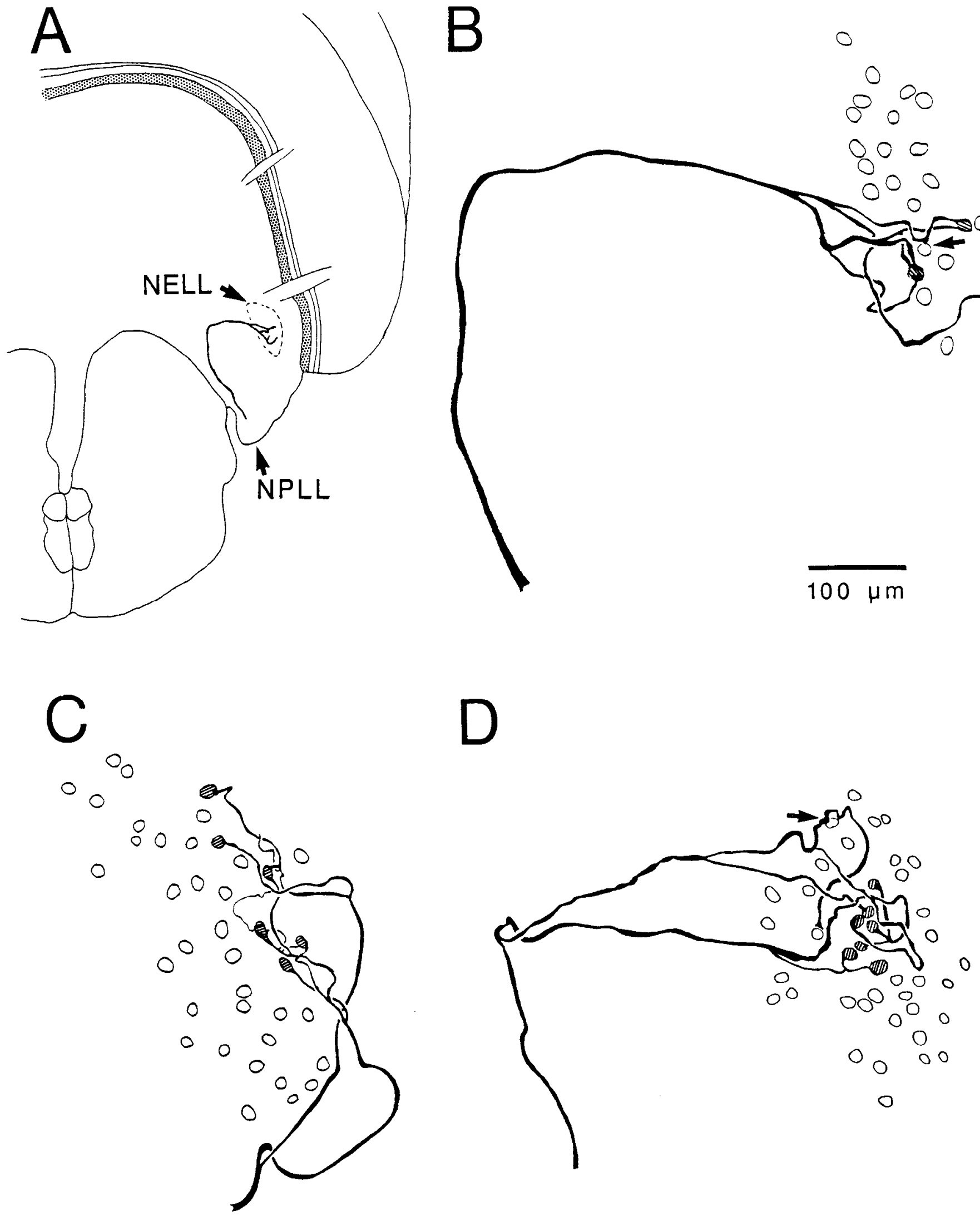

Figure 2. Camera lucida drawings of filled knollenorgan afferents terminating in NELL. $A$, Transverse section through the medulla showing the location and orientation of the drawn fibers. $B-D$, Three different knollenorgan afferents. The fiber shown in $A$ is repeated at a higher magnification in $B$. The open circles are cells and indicate the borders of the nucleus. The cells on which terminals could be clearly identified are indicated by crosshatching. The solid arrows in $B$ and $D$ indicate close appositions between the labeled fiber and an NEI $I$, cell which may have been en passant terminals. The scale bar in $B$ applies to $C$ and $D$ also. $N E L L$, nucleus of ELL; $N P L L$, posterior lateral line nerve. 

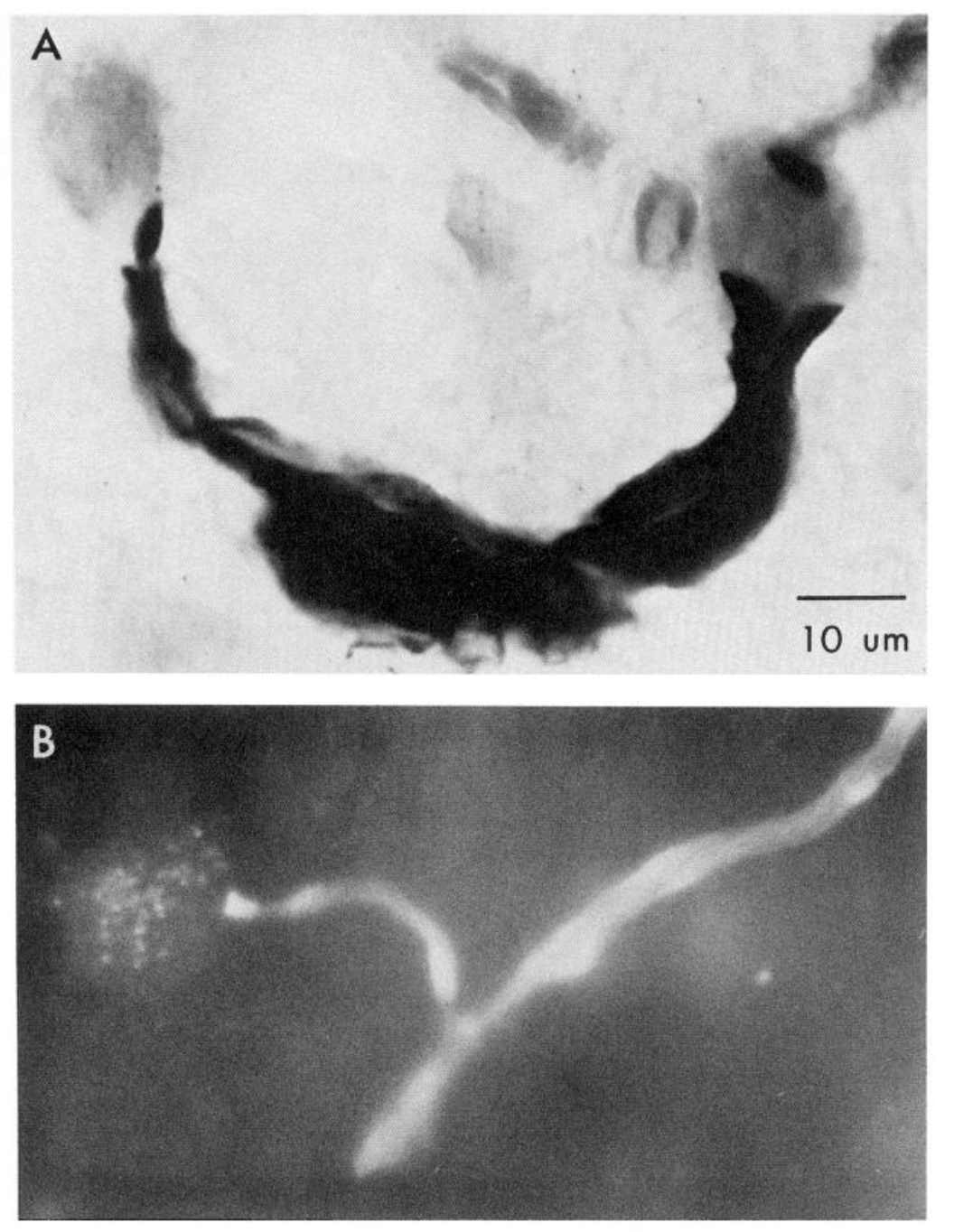
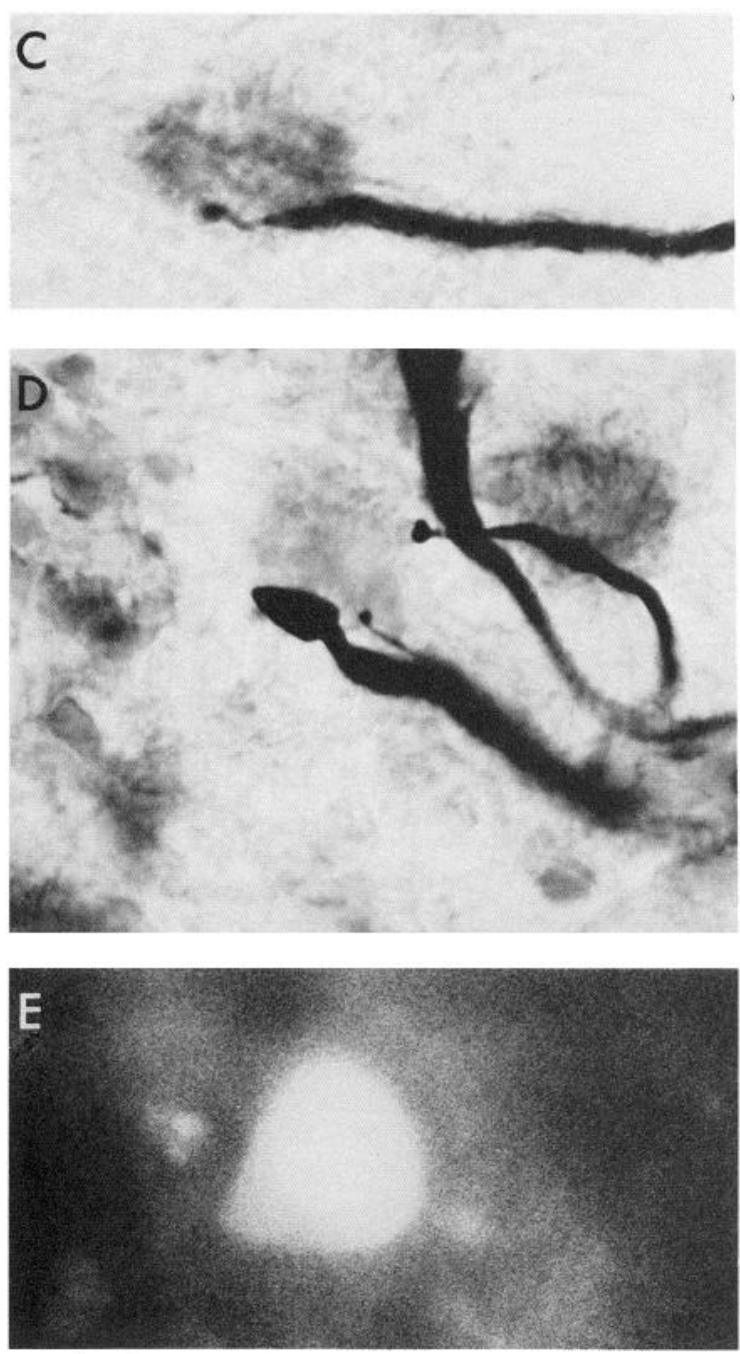

Figure 3. Labeled knollenorgan afferent terminals and cells in NELL. A, HRP-labeled terminals on cells. The same afferent contacts both the cell on the left and the cell on the right. The cell on the right has 3 large terminals from the same afferent: an upper one that is slightly out of focus and 2 lower ones that are barely distinguishable from each other in the photograph. $B$, Lucifer yellow-stained fiber contacting a cell. The granules in the cell are due to autofluorescence, not to Lucifer yellow. $C$, HRP-labeled terminals on a cell. A large terminal gives off a thin branch that ends as a small terminal on the same cell. $D$, HRP-labeled terminals on a cell. A single afferent provides 1 large and 2 small terminals to the same cell. $E$, A cell of NELL filled with Lucifer yellow.

riorly beneath the medial octavolateral nucleus. There it divided, with one branch entering the ipsilateral component of the lateral lemniscus and the other crossing the midline to enter the contralateral component. This trajectory confirms earlier indications of branching that were based on extracellularly injected HRP (Bell et al., 1981; Szabo et al., 1983).

\section{Physiology}

Field potentials

Field potentials associated with the EOD motor command, i.e., corollary discharge potentials, are prominent throughout the ELL. Potentials due to corollary discharge activity in the mormyromast and ampullary regions of the cortex are recorded in and near NELL because of volume conduction from the nearby cortical regions. Within NELL, however, one also records a brief, positive-negative corollary discharge field potential that is well localized to the nucleus (Fig. $4 B$ ). This extracellular potential was used to locate NELL at the start of each experiment for subsequent placement of the intracellular electrodes.
A second and similarly brief extracellular potential is evoked in the same region by electrosensory activation of knollenorgan afferents (Fig. 4A). The low threshold and near absence of any latency shift as stimulus intensity is increased above threshold indicate the knollenorgan origin of this evoked potential (Bennett, 1965). Finally, a small potential evoked by antidromic activation from the mesencephalon was occasionally observed within NELL. The corollary discharge and antidromic potentials were more sharply localized to NELL than was the potential evoked by electrosensory stimulation. The less restricted distribution of the sensory evoked response is consistent with its being generated by impulses in the afferent fibers.

The latency of the electrosensory potential with respect to the stimulus and the latency of the corollary discharge potential with respect to the command signal varied in a roughly corresponding manner along the rostral caudal length of NELL (Fig. 4). The latency of the electrosensory evoked potential was shorter in the rostral part of NELL, which receives afferent input from the head, than it was in the caudal part, which receives 

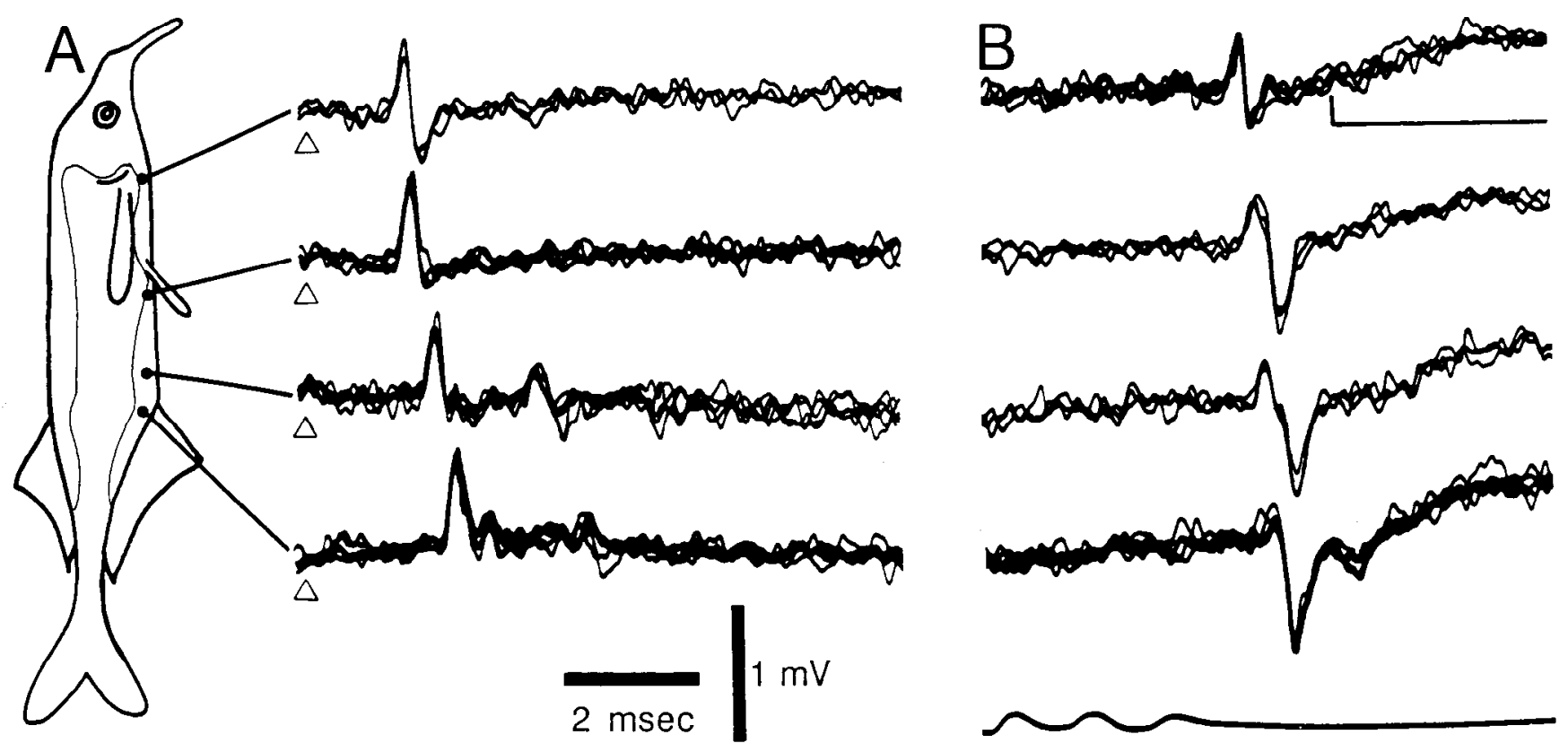

Figure 4. Corollary discharge and electrosensory evoked field potentials in NELL recorded at 4 different sites along the rostrocaudal axis of NELL. The most rostrally recorded potentials are at the $\iota p p$ and the most caudally recorded potentials are at the bottom. $A$, Potentials evoked by local electrosensory stimuli. The time of the electrosensory stimulus is indicated by an open triangle $(\triangle)$ in this and subsequent figures. The drawing on the left indicates the stimulation points on the skin surface for each response. These were also the points of lowest threshold for evoking a field potential at the recording site. $B$, Corollary discharge potentials recorded at the same NELL sites as the potentials in $A$. All sweeps triggered by the pre-EOD electromotoneuron volley ("command signal") shown in the bottom trace. The fast positive-negative evoked potential is localized to NELL, but the later and slower positive potential (bracket in top record of $B$ ) is not. Horizontal and vertical calibration bars are valid for NELL recordings in both $A$ and $B$. The peak-to-peak amplitude of the command signal (bottom trace in $B$ ) in this and in subsequent figures was between 0.1 and $0.2 \mathrm{mV}$ (exact voltage calibrations are not given for command signal traces).

afferent input from the skin near the tail, due to differences in conduction time from near and far regions of the skin (Fig. 4A). The latency of the corollary discharge potential was also shorter at more rostral sites in NELL (Fig. 4B). This second latency difference might also be due to conduction time variations but in a different set of fibers, namely, those fibers responsible for the corollary discharge (see Discussion). A rough correspondence similar to that shown in Figure 4 was seen in all 5 fish in which the phenomenon was examined.

\section{Overview of intracellular recordings}

The intracellular recordings fell into 3 distinct types, and these could be identified with the 3 different morphological elements of the nucleus. Intracellular labeling identified one of these types as originating from primary knollenorgan afferents and a second type as originating from NELL cells. The third type of recording almost certainly originated from the fibers responsible for the corollary discharge inhibition, but these elements could not be successfully labeled with intracellular staining. The knollenorgan afferent type of recording was observed in recordings from the root of the posterior lateral line nerve, but neither of the other 2 types of NELL recordings was observed in the nerve.

\section{Intracellular recordings from primary knollenorgan afferents}

The major features described here as characteristic of knollenorgan afferents were found in 152 different intracellular recordings, including 18 recordings from the root of the posterior lateral line nerve. These features were present in all 15 of the elements that were successfully labeled and identified morphologically as primary afferents.

The recordings showed a stereotyped corollary discharge driven hyperpolarization or ipsp occurring just after each command signal (arrows, Figs. 5, B, C). The latency, amplitude, and duration of the ipsp were highly consistent within a given fiber and did not vary greatly among fibers. Among different fibers, the latency between the first positive peak of the command signal and the start of the ipsp ranged between 5 and $7 \mathrm{msec}$, the amplitudes ranged between 0.5 and $3.0 \mathrm{mV}$, and the durations ranged between 3 and $6 \mathrm{msec}$.

The recordings showed 2 distinct types of orthodromic events, both of which could be elicited by electrosensory stimulation of the skin. The first type was a large spike with an amplitude between 20 and $70 \mathrm{mV}$ (an example is labeled "iii" in Fig. 5B). Sometimes there was an overshoot, with the spike height being greater than the membrane potential. The large size of this spike, the abrupt rise, and the finding that the corollary discharge ipsp had no effect on its amplitude (as described below) indicated that the spike must be the orthodromic spike of the recorded afferent fiber.

The second type of orthodromic event was also all-or-none but was much smaller in amplitude $(0.5-8.0 \mathrm{mV})$ than the large spike (examples are labeled "i" and "ii" in Fig. $5 B$ ). The amplitude of the small orthodromic events was never more than $1 / 8$ th of the large spike amplitude. Two or 3 such small events with different amplitudes could usually be recorded within each fiber.

The durations, latencies, and thresholds of the small ortho- 

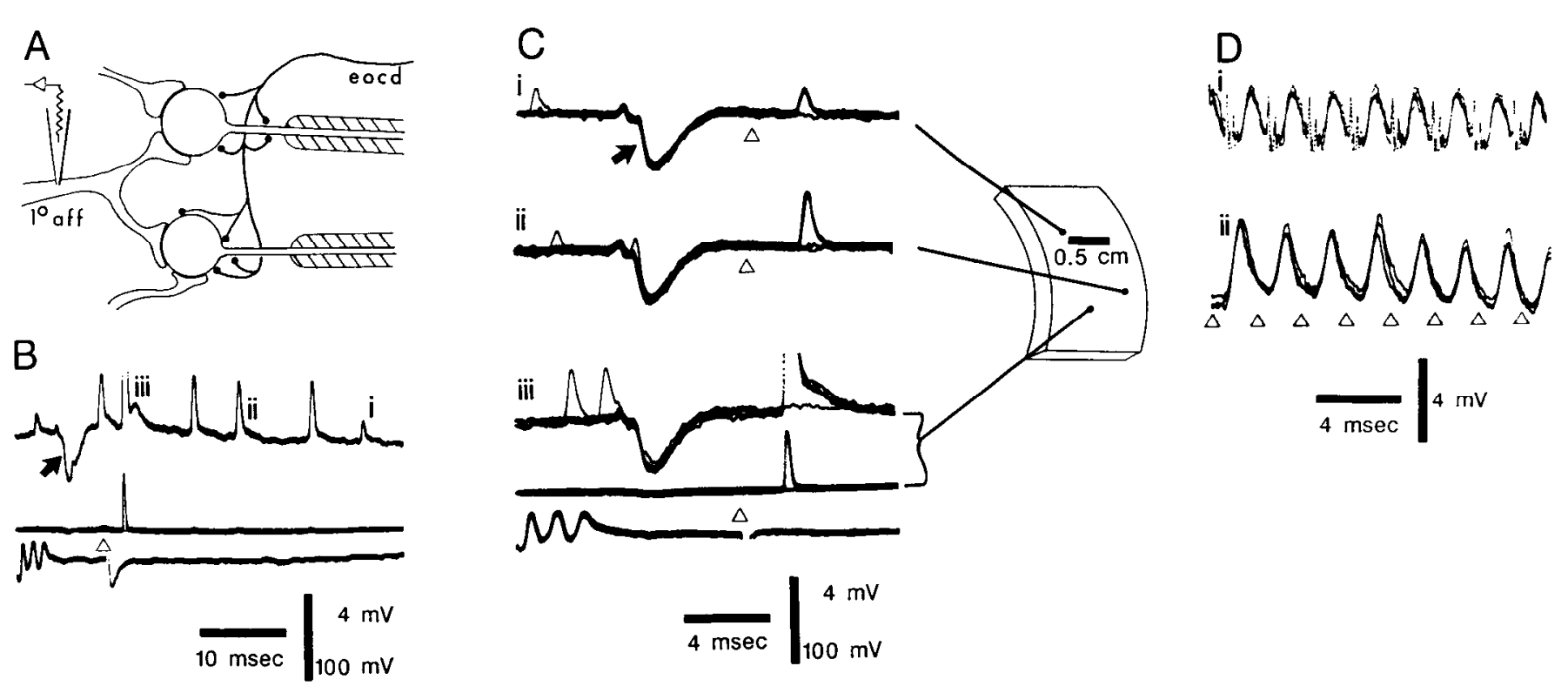

Figure 5. Intracellular recordings from knollenorgan afferents: large afferent spikes and synaptic events. $A$, Schematic drawing of connections in NELL. Primary knollenorgan afferents $\left(1^{\circ} a f f\right)$ and the fiber responsible for the electric organ corollary discharge $(e o c d)$ synapse on NELL cells. $B$, Large afferent spike, 2 sizes of electrotonic epsps, and corollary discharge ipsp in the same afferent. The traces were triggered by the command signal shown in the bottom trace. The high-gain (top) trace shows 2 sizes of spontaneously occurring electrotonic epsps ( $i$ and $i i)$, the large afferent spike (iii), and the corollary discharge ipsp (black arrow). The low-gain (middle) trace shows the large afferent spike. This afferent spike was evoked by an electrosensory stimulus $(\Delta)$. The sweeps were triggered by the command signal shown in the bottom trace. $C$, Two electrotonic epsps $(i$ and ii) and the large afferent spike (iii) shown in $B$ arise from different spots on the skin surface. Superimposed traces were recorded from the same primary afferent fiber as in $B$ and triggered by the command signal. Large arrow points to corollary discharge ipsp. Local stimuli were at the skin sites indicated in the drawing at the right. Stimuli were at threshold for eliciting an event as indicated by the failure of an event to occur in some sweeps. Threshold stimulation at each site elicited a different all-or-none event. The smaller epsp occurred spontaneously in $i$ and $i i$ and the larger epsp occurred spontaneously in iii. Records in iii include a high-gain (top) and a low-gain (middle) trace. $D$. High following frequency of electrotonic epsps to local electrosensory stimuli. Two epsps from 2 different fibers each follow the stimulus at about $500 / \mathrm{sec}$. Time of stimulus is shown by shock artifacts in $i$ and by open triangles in ii. In this and in subsequent figures, the value of the voltage calibration bar for the high-gain trace is written above the value for the low-gain trace.

dromic events were similar to those of the large spike. Both the large spike and the small orthodromic events could occur spontaneously (Fig $5 B$ ), as well as in response to electrosensory stimulation (Fig. 5C).

It was usually possible to find points on the skin surface at which localized electrosensory stimuli could elicit either the large spike or one of the small orthodromic events in isolation, as shown by varying the stimulus intensity back and forth across threshold (Fig. 5C). Effective stimulation points for a given fiber, in which each point yielded a different response, were separated by $0.5-2.5 \mathrm{~cm}$, as shown at the right of Figure $5 C$. In 3 fibers, the separate electroreceptors giving rise to the large spike and to at least one of the small orthodromic events could be identified.

Both the large spike and the small orthodromic events responded to each stimulus up to stimulus presentation rates of about $500 / \mathrm{sec}$, as shown in Figure $5 D$ (small events only). The refractory period, as tested with 2 stimulus pulses, was about $1.2 \mathrm{msec}$ for both types of events.

These results and the anatomical identification of large gap junctions between knollenorgan afferents and NELL cells (Szabo et al., 1978, 1983; Mugnaini and Maler, 1987b) suggest that the corollary discharge ipsp and the small orthodromic events are synaptic inputs to NELL cells that are recorded inside knollenorgan afferents via the large electrical synapses. One electron microscopic study does describe synaptic endings on the synaptic terminals of knollenorgan afferents (Szabo et al., 1983), but these endings did not appear to be prominent; a second similar study failed to find such endings (Mugnaini and Maler, 1987b). In contrast, both studies found that synaptic terminals on the postsynaptic cells of NELL were extremely dense.

The small orthodromic events are probably electrotonic epsps caused by the arrival of impulses at the terminals of other knollenorgan afferents that end on some of the same cells as does the recorded afferent (see diagram of Fig. 5A). This is indicated by the similarity of the latencies and thresholds of the different small orthodromic events to those of the large afferent spike and by the origin of the small orthodromic events from separate skin regions or separate electroreceptors.

Large afferent spikes were sometimes followed by an afterhyperpolarization. It seems likely that the hyperpolarization following the large afferent spike is associated with the spikegenerating process in the afferent and does not represent a synaptically mediated inhibition. This interpretation is consistent with the lack of hyperpolarization when electrosensory stimuli were positioned so as to elicit only electrotonic epsps or positioned just outside the area for eliciting any excitatory responses. A lack of surround inhibition is also consistent with the morphology which indicates that there are no interneurons or recurrent collaterals of NELL cells in NELL.

Antidromic responses of NELL cells to stimulation in the mesencephalon are also recorded inside primary afferents. The recording of such postsynaptic cell spikes further supports the idea that events occurring in the second-order cells may be 

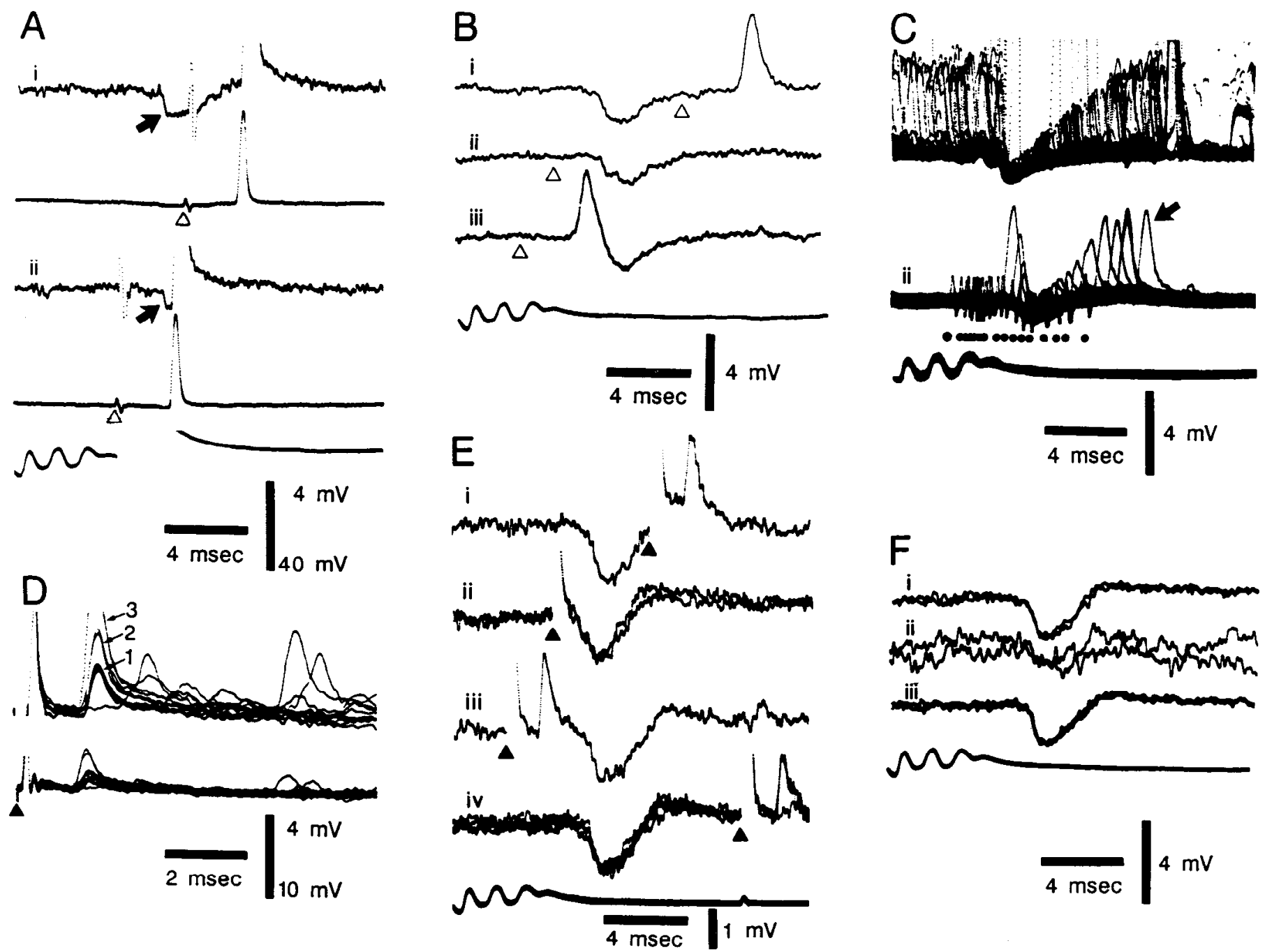

Figure 6. Intracellular recordings from knollenorgan afferents: effects of corollary discharge inhibition. Sweeps triggered by command signal in $A-C, E$, and $F . A$, Absence of effect on large afterent spike. The large afferent spike is the same whether it occurs at the peak of the ipsp (ii) or after the ipsp (i). Both high- and low-gain traces are shown for $i$ and ii. Large arrows point to corollary discharge ipsp. $B$, Electrotonic epsp is greatly reduced by ipsp. This shows the same fiber as in $A$ but with the local stimulus at a different site. The epsp evoked by stimulation at this site is large when it occurs after $(i)$ or before (iii) the ipsp but is almost completely blocked when it occurs during the ipsp (ii). $C$, Superimposed traces of epsps show time course of inhibition. The top trace (i) shows spontaneously occurring epsps, whereas the middle trace (ii) shows evoked epsps. The evoked epsp is indicated by an arrow. I arge afferent spikes occurred spontaneously during the ipsp in the top trace and are visible as vertical rows of fine dots. The effects of electrosensory and intracellular stimuli are visible at the right of the same trace. The times of electrosensory stimuli in the middle trace (ii) are indicated by small black dots and by the small biphasic shock artifacts. $D$, Afferent fiber with 3 discrete levels of response to antidromic stimuli (1-3). Superimposed traces. The 2 lower levels are best seen in the high-gain (top) trace, whereas the highest level is best seen in the low-gain (bottom) trace. Spontaneous activity was present in this afferent. The antidromic stimulus was given at the start of the sweep. The time of an antidromic stimulus is indicated by a flled triangle $(\boldsymbol{\Lambda})$ in this and subsequent figures. $E$, Antidromic response blocked by ipsp. This shows a different fiber from that shown in $D$. The antidromic response can occur after ( $i$ and $i v)$ or before (iii) the ipsp but is absent during the ipsp $(i i)$. The stimulus in $i v$ was reduced with respect to that in $i$-iii to a near-threshold level to illustrate the all-or-none character of this antidromic response. $F$, Reduction of ipsp in afferent by hyperpolarizing current. The ipsp is prominent before $(i)$ and after $(i i i)$ hyperpolarization but not during the hyperpolarization (ii).

observed in recordings from primary afferents because of the electrical synapses. The antidromic responses were small $(0.5-$ $3.0 \mathrm{mV}$ ), usually smaller than the electrotonic epsps recorded in the same fiber, and had latencies of $1.5-2.0$ msec. In some fibers, only a single all-or-none antidromic spike was recorded (Fig. $6 E$, iv); in other fibers, changes in stimulus intensity revealed the presence of 2 or 3 discrete levels in the response (Fig. $6 D$ ). The different levels are inferred to be the antidromic responses of different NELL cells contacted by the recorded afferent.

The electrotonic epsps and the antidromic responses are markedly reduced by the corollary discharge ipsp (Fig. 6, B, C, $E$ ). The inhibitory effect is greatest when the ipsp reaches its maximum, and inhibition often appeared total at this time (Figs. $6 C$, i; $E$, ii). The effective duration of the inhibition often appeared to be about the same as that of the ipsp, i.c., 3-5 msec. In some fibers, however, the amplitudes of the antidromic responses or of the small orthodromic events were slightly reduced for as long as $10 \mathrm{msec}$ (Fig. $6 C$, i).

The large afferent spike is only minimally affected by the ipsp, however (Fig. 6A). The ipsp sometimes caused a slight reduction in the duration of the afferent spike but did not affect its am- 

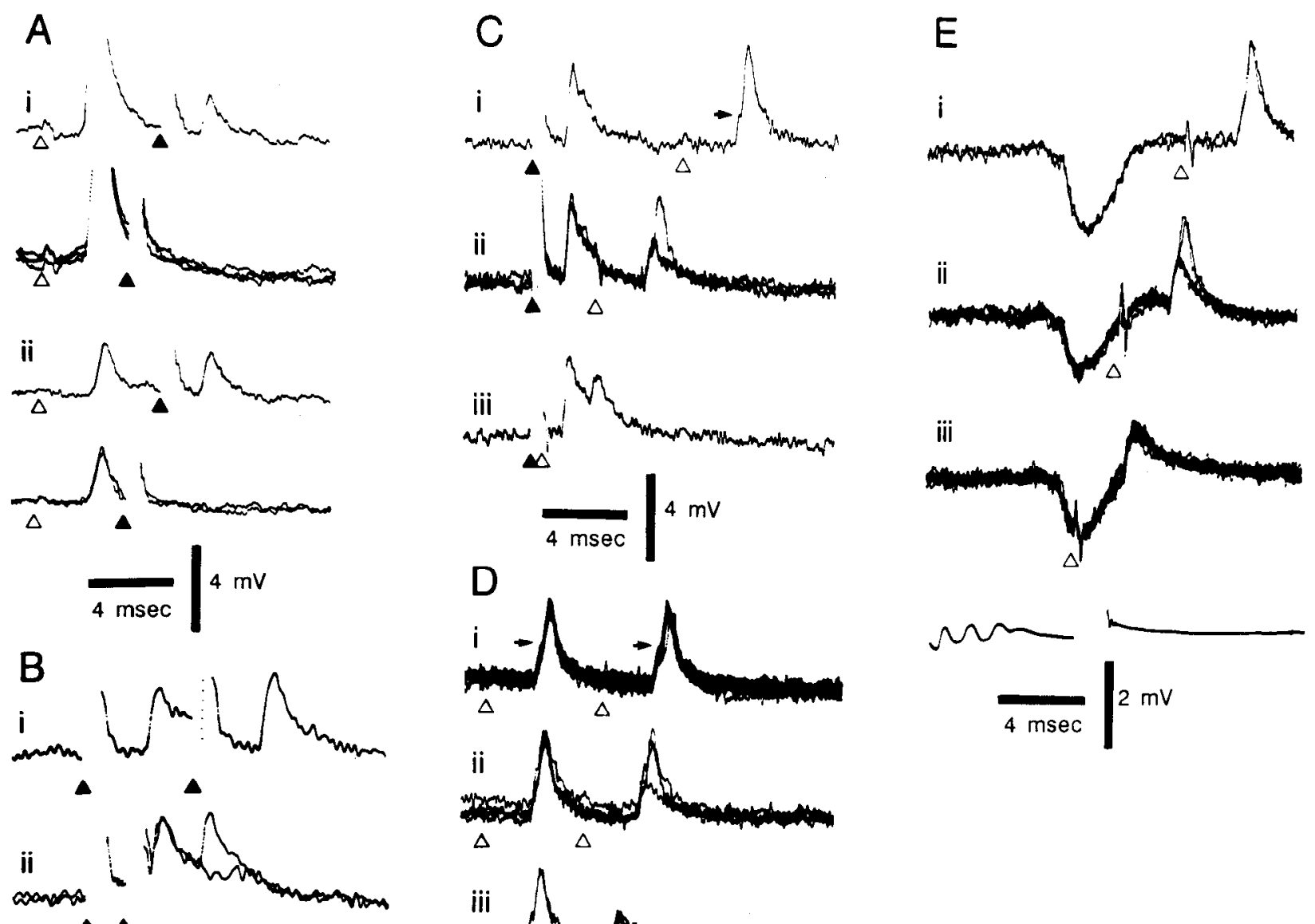

$\Delta \boldsymbol{\Delta}$

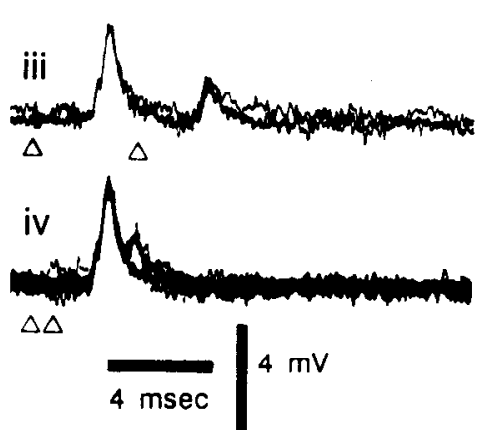

Figure 7. Intracellular recordings from knollenorgan afferents: identification of orthodromic NELL cell spike. $A$, Collision between orthodromic and antidromic NELL cell spikes. An orthodromic stimulus $(\Delta)$ is followed by an antidromic stimulus $(\boldsymbol{\Delta})$. $i$, The antidromic response is present at long delays following a large afferent fiber spike (top trace) but is blocked at short delays of about 4 msec (bottom trace). $i$, The antidromic response in the same fiber is also blocked following a smaller orthodromic response elicited from a different stimulus location. $B$, Refractory period for antidromic spike. $i$, The response to the second of 2 identical antidromic stimuli is present at long delays. $i i$, The response to the second antidromic stimulus is blocked at short delays of about $1.2 \mathrm{msec}$. $C$, Blocking of an all-or-none component of an orthodromic response by a preceding antidromic response. A horizontal arrow points to an inflection on the rising phase of the orthodromic response. $i$, Both components are present at long delays. $i$, A second component fails at short delays. $i i i$, The first component of the orthodromic response, which is probably the electrotonic epsp isolated from the NELL cell spike, is not affected by the preceding antidromic response. $D$, Two components to the orthodromic response are also made visible by pairing 2 identical orthodromic stimuli. This shows the same fiber as that in $B$. $i$, Both orthodromic components occur at long delays. $i i$, The second component begins to fail at shorter delays. iii, Only the first component occurs at still shorter delays. $i v$, The first component also fails at the shortest delays due to refractoriness in the presynaptic axon. $E$, Two components of the orthodromic response are also made visible by giving an orthodromic stimulus at various times with respect to the corollary discharge inhibition. $i$, Both components are present at long delays with respect to the command signal. $i i, \Lambda$ second component sometimes fails to occur at shorter delays. $i i i$, Only the first component occurs at still shorter delays.

plitude. The marked difference in effect of the ipsp is probably because the current responsible for the epsps or antidromic responses must pass through the inhibited second-order cell to reach the recording site in the afferent fiber, whereas most of the current responsible for the afferent spike recording does not pass through the second-order cell. The slight thinning of the afferent spike could be due to an increased conductance during the ipsp and a consequent reduction in the time constant near the terminals. Intracellular hyperpolarizing current caused a flattening of the ipsp (Fig. $6 F$ ), but it was not possible to cause an inversion of the ipsp (5 fibers tested).

Some recordings from primary afferents revealed what appeared to be a depolarization immediately following the corollary discharge ipsp (Fig. 6, $F, F$ ). Large, positive-going field potentials due to corollary discharge activity are present at this time in nearby mormyromast and ampullary regions, however, 
Figure 8. Intracellular recordings from NELL cells: corollary discharge ipsp, orthodromic events, and antidromic response. $A$, Diagram showing recording site. $B$, Inverted corollary discharge ipsps and spontaneously occurring orthodromic events in 2 different cells. The sweeps are triggered by the command signal. At least 2 sizes of orthodromic events are present in the lower trace. An arrow points to the inverted ipsp in the upper trace. $C$, Four different levels of orthodromic responses and an antidromic response in the same cell. The traces were triggered by the command signal and show an inverted corollary discharge ipsp (arrow in top trace). $i$, Progressive increases in the intensity of an electrosensory stimulus reveals 3 different levels of orthodromic responses (final level shown best in the low-gain trace). $i i$, An additional increase reveals a fourth and largest orthodromic response (also shown best in the low-gain trace). iii, A stimulus to the exterolateral nucleus of the mesencephalon elicits an all-or-none antidromic response that is smaller than 2 of the orthodromic responses.
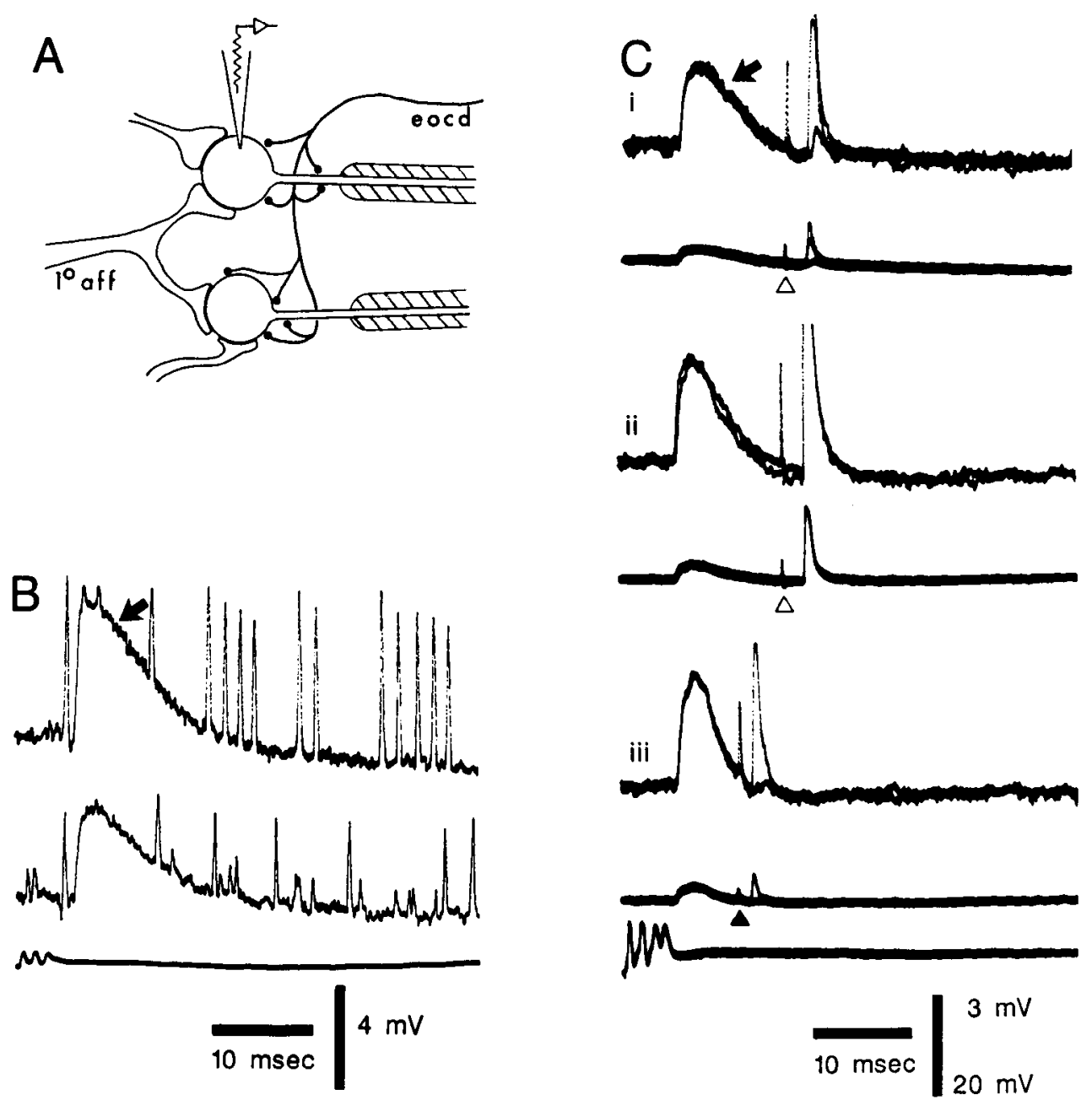

and these signals are recorded in NELL by volume conduction (slowly rising potentials indicated by the bracket at right in Fig. $4 B$ ). No clear intracellular depolarization could be demonstrated when intracellular records were carefully compared with the field potentials recorded just outside the cell. Nevertheless, there did seem to be a period of enhanced excitability immediately following the ipsp that might be due to a post-anodal enhancement of excitability. On occasion, electrotonic epsps or the large afferent spikes occurred at this time in the absence of electrosensory stimuli, due presumably to an activation of afferent terminals on the rebound from the ipsp. Whether such activation occurs in the absence of damage depolarization caused by the electrode is not known.

The orthodromically elicited spikes of NELL cells, as recorded in primary afferents, were small in size and occurred at such short latencies following electrosensory stimulation as to overlap in time the large afferent spikes or electrotonic epsps. The small size and temporal overlap meant that the presence of an orthodromic postsynaptic spike could usually be established only by collision with an antidromically elicited spike. Figure $7 A$ shows 2 examples of such collisions recorded in the same primary afferent. The small antidromic spike failed to occur when preceded by either the large afferent spike (Fig. $7 A$, i) or by an electrotonic epsp (Fig. $7 A$, ii) evoked by stimulation at a different skin location. The delay between the occurrence of the afferent spike or electrotonic epsp and the time at which the antidromic spike failed was always close to twice the conduction time for the antidromic spike plus the refractory period of the antidromic spike (Fig. $7 B$ ), as required for demonstration of collision.

The fact that the same all-or-none antidromic spike was blocked by both the large afferent spike and by the electrotonic epsp means that impulses in either the recorded fiber or in the fiber responsible for the electrotonic epsp could make that cell discharge. Temporal summation of epsps from different afferents was therefore not required for spike generation in the second-order cell. Similar results were obtained in 10 different fibers. In 2 of these, the occurrence of the large afferent spike or either of 2 different electrotonic epsps resulted in the block of an all-or-none antidromic spike, suggesting that any 1 of 3 different inputs could make some NELL cells discharge.

In a few cases, the orthodromic cell spike could be observed more directly than with collision and could be separated from the electrotonic epsp that elicited it. In Figure $7 C$, ii, a component of the orthodromic response fails to occur when the orthodromic response follows the antidromic spike at short delays. The component that fails is similar in wave form to the antidromically elicited spike and probably represents the orthodromic cell spike. A smaller component, presumably the electrotonic epsp, is not affected by the preceding antidromic spike (Fig. $7 C$, iii). Figure $7 D$, ii and iii, from the same fiber, show a similar component failure but a failure caused by a 
A
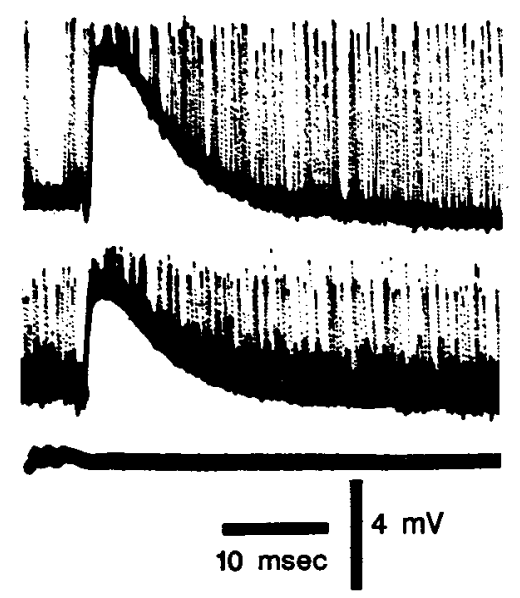

B
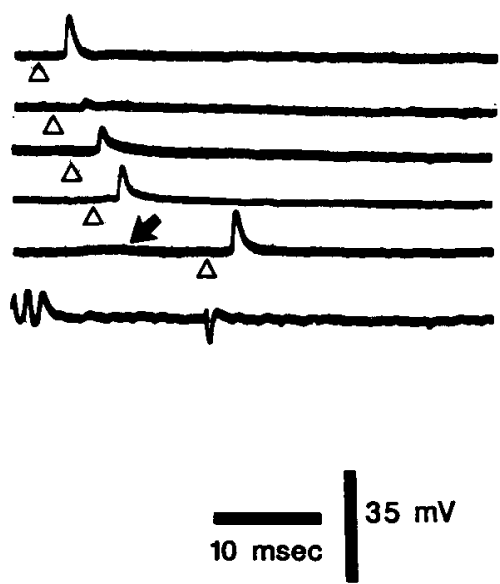

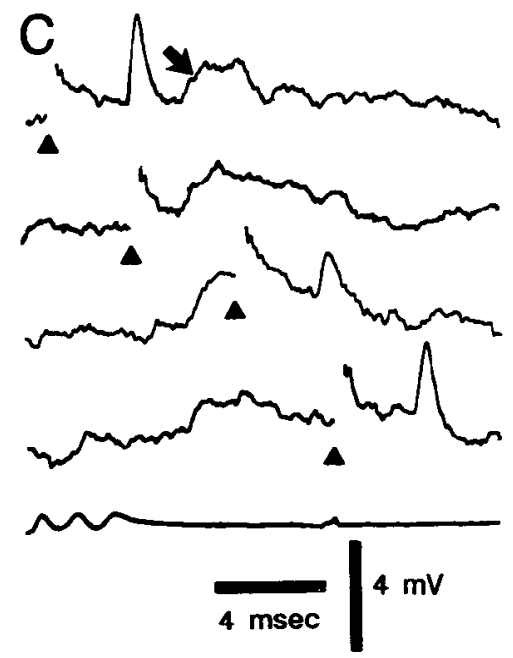

Figure 9. Intracellular recordings from NELL cells: effect of corollary discharge ipsp on orthodromic and antidromic responses. All sweeps are triggered by the command signal. $A$, Reduction in amplitude of spontaneously occurring orthodromic events during ipsp. These are the same cells as those shown in Figure $8 B$ but with superimposed traces. $B$, Large orthodromic response is blocked by ipsp. The inverted ipsp has fallen to a low level and is only visible as a slight upward deflection (arrow in the next to last trace). $C$, Reduction in amplitude of antidromic response during ipsp. The inverted ipsp (arrow in top trace) is small, and the record is noisy.

preceding and identical orthodromic response. In this case, the underlying electrotonic epsp can be blocked at the stimulus interval of $1.2 \mathrm{msec}$ due to refractoriness in the afferent fiber (Fig. $7 C$, iv).

The presence of 2 components in the orthodromic response was also sometimes revealed by pairing an orthodromic stimulus with the corollary discharge inhibition, the 2 components being once again the electrotonic epsp and the postsynaptic spike (Fig. $7 E$ ). The corollary discharge inhibition presumably reduced the electrotonic epsp to near threshold for the postsynaptic spike in the swecps of Figure $7 E$, ii and reduccd it to bclow threshold in the sweeps of Figure $7 E$, iii. Support for this interpretation was obtained through collision with a small antidromic spike (not illustrated). Collision with the antidromic spike occurred in this fiber when the second component was present (in Fig. $7 E$, i) but not when it was absent (Fig. $7 E$, iii). Inflection points are present on the rising phase of the small orthodromic events in these records (horizontal arrows in Fig. 7, $C, D$ ). Such inflection points were also seen in other cells and probably represent the onset of an orthodromic NELL cell spike from an underlying electrotonic epsp.

\section{Intracellular recordings from NELL cells}

The major features described here as characteristic of NELL cells were found in 18 different intracellular recordings, of which 3 were morphologically identified as NELL cells.

As previously discussed, the synaptic and antidromic potentials observed inside primary afferents probably reflect events occurring inside the postsynaptic cells of NELL, and the recordings from NELL cells were, in fact, quite similar to the recordings from afferents. There were 3 major differences, however, between the afferent recordings and the cell recordings:

1. The corollary discharge ipsp was of much longer duration in the cells than in the afferents (10-18 vs. $3-6$ msec; Figs. 8 , 9, 11).

2. This corollary discharge ipsp always inverted from a hyperpolarizing to a depolarizing potential whenever there were chloride ions in the recording electrode (Fig. 8, B, C). This inversion occurred within a few seconds following penetration. The long-duration ipsps observed in these elements did not invert when recorded with potassium acetate electrodes (Fig. $11 \mathrm{~B}$ ). In contrast, the brief ipsps of afferent fiber recordings never inverted when recorded with chloride-filled electrodes.

3. All of the orthodromic responses in cells were greatly reduced by the corollary discharge ipsp (Fig. 9, $A, B$ ). That is, there was no event equivalent to the large afferent spike of the presynaptic fibers.

Between 1 and 4 different orthodromic events could be discriminated in cach cell on the basis of amplitude (Fig. 8, B, C). The amplitudes ranged from 0.5 to $20 \mathrm{mV}$, but most were between 2 and $8 \mathrm{mV}$. These amplitudes were, in general, greater than the amplitudes of the electrotonic epsps recorded inside primary afferents. As in the primary afferents, different orthodromic events could be elicited independently by changing the point of stimulation on the skin surface by a few centimeters. Thus, many of the different discrete orthodromic events were probably electrotonic epsps evoked by different knollenorgan afferents.

The number of different levels of orthodromic responses cannot be taken as the number of different afferents that terminate on a recorded cell, however. Some of the discrete changes in amplitude could be due to the occurrence of postsynaptic cell spikes (see below), and some of the afferents impinging on a cell might not have been stimulated or discriminated. A convergence of 3 or 4 afferents onto each NELL cell is perhaps a reasonable estimate, however, given the morphological results indicating that each cell has a very limited number of terminals (Bell and Russell, 1978; Szabo et al., 1983; Mugnaini and Maler, $1987 \mathrm{~b}$ ) and that the same fiber can have more than one terminal on a single cell, as previously noted.

Antidromic responses were obtained from 4 cells (Figs. $8 C$, iii; $9 C ; 10)$. They were all-or-none responses of $2-4 \mathrm{mV}$, and none showed the multiple levels of response observed in the afferent fibers. The antidromic responses were always smaller than the largest orthodromic events recorded in the same cells.

The corollary discharge ipsp was not only longer in duration 


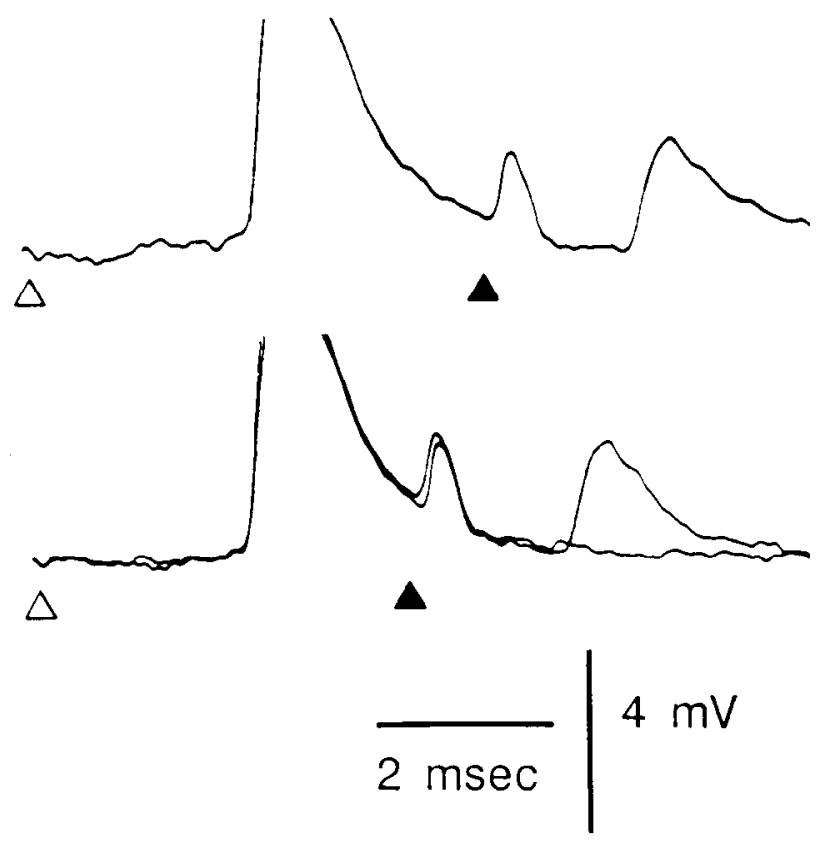

Figure 10. Intracellular recording from an NELL cell: identification of an orthodromic NELL cell spike by collision. Top trace, An orthodromic electrosensory stimulus elicits a response, and this response is followed by an antidromic stimulus which also elicits a response. Bottom trace, Antidromic stimulus fails to elicit a response when given at a short delay $(4 \mathrm{msec})$. The antidromic stimulus elicits a response in one sweep but fails to elicit a response when given $0.1 \mathrm{msec}$ earlier in a second sweep. The brief positivity that begins at the time of the antidromic stimulus is a shock artifact.

in the cells than in the afferent fibers but was also larger in amplitude. In most cells, the ipsp inverted too rapidly to measure its preinversion amplitude. In one cell, however, this level was $7 \mathrm{mV}$, and in one of the cells recorded with potassium acetate electrodes, the amplitude was $6 \mathrm{mV}$. These values are 2 or more times the largest amplitudes observed inside the afferent fibers.

Both orthodromic and antidromic events were markedly reduced by the corollary discharge ipsp. The reduction in amplitude appeared to last as long as the ipsp (Fig. 9). As with the afferent fibers, the maximum inhibition occurred at the peak of the ipsp (Fig. 9). The reduction in amplitude of the electrotonic epsps and antidromic responses indicates an underlying increase in conductance during the ipsp.

As described in the results on primary afferent recordings, the orthodromic cell spike appeared to have a very short latency following the onset of an electrotonic epsp and to overlap the epsp in time. The orthodromic spike could only be demonstrated in NELL cells by collision with an antidromic spike (Fig. $10)$.

\section{Intracellular recordings from fibers that are probably responsible for the corollary discharge inhibition}

The third type of element recorded in NELL gives a single spike at a short, fixed latency following the command signal (Fig. 11B, i). These command signal-related spikes are the only spikes present. This element does not respond at all to orthodromic or antidromic stimulation. Nineteen elements of this type were recorded, but none were successfully labeled.

The spike in these fibers always occurred about $1 \mathrm{msec}$ before the onset of corollary discharge ipsps in afferent fibers (Fig. $11 B$, iii) or in cells (Fig. $11 B$,ii) recorded in the same electrode track. The consistent timing of these spikes in relation to ipsps recorded nearby and the localization of these single spike fibers to the region of NELL strongly suggest that this fiber is responsible for the corollary discharge inhibition in NELL. The observed synaptic delay of $1 \mathrm{msec}$ is within the range of what would be expected for a chemical synapse in a cold-blooded vertebrate at a room temperature of $23^{\circ} \mathrm{C}$ (Bennett, 1977).

\section{Discussion}

The nucleus of the NELL appears to subserve 2 functions: providing a locus for the corollary discharge inhibition at the first stage of central processing and faithfully relaying temporal information to the mesencephalon.

\section{Corollary discharge inhibition}

Zipser and Bennett (1976) recorded intracellularly from elements within the ELL. Some of these elements gave a large orthodromic spike in response to knollenorgan activation. The spike was completely blocked for a few milliseconds following the command signal. These elements did not show the corollary discharge ipsp or small orthodromic events that we consistently recorded in the knollenorgan afferents and cells of NELL, and the recorded elements were not identified morphologically. Zipser and Bennett may have been recording from the axons of NELL cells.

The duration of the corollary discharge inhibition observed by Zipser and Bennett (1976) was between 3 and 5 msec. Even shorter durations for this inhibition have been found in other studies that examined the effect of the EOD motor command on evoked potentials in the anterior exterolateral nucleus of the mesencephalon (Bennett and Steinbach, 1969; Russell and Bell, 1978; Szabo et al., 1979). These durations are all shorter than the $10 \mathrm{msec}$ inhibition we observed in the cells of NELL and in some of the afferent fibers. The difference in duration of inhibition can be explained by noting that the studies of Zipser and Bennett, and the studies of evoked potentials in the anterior exterolateral nucleus, showed the effect of the inhibition on the spike output of NELL cells. These studies also used high stimulus intensities, which would activate all of the knollenorgan afferents. Our intracellular recordings suggest that the threshold for orthodromic spikes in NELL cells is well below the amplitude of most electrotonic epsps so that transmission through the nucleus of the response to intense stimuli would be blocked only when the inhibition is close to a maximum, i.e., during the first few milliscconds of the ipsp.

As described in our introductory remarks, immunocytochemistry shows closely packed GABA- and GAD-containing terminals on the cell bodies and long initial segments of NELL cells (Denizot et al., 1987; Mugnaini and Maler, 1987b), indicating that GABA is probably the inhibitory transmitter responsible for the corollary discharge inhibition. The finding that the ipsp inverted when NELL cells were recorded with chloridecontaining electrodes is consistent with GABA being the transmitter and suggests that the receptor is of the GABAa type in which chloride channels are opened (Alger, 1985). A recent finding that bicuculline blocks the corollary discharge inhibition of knollenorgan input is a further indication that the inhibition is mediated by GABA and GABAa receptors (K. Grant, E. Thoreau and C. C. Bell, unpublished observations).

Mugnaini and Maler (1987b) suggested that the spike initi- 

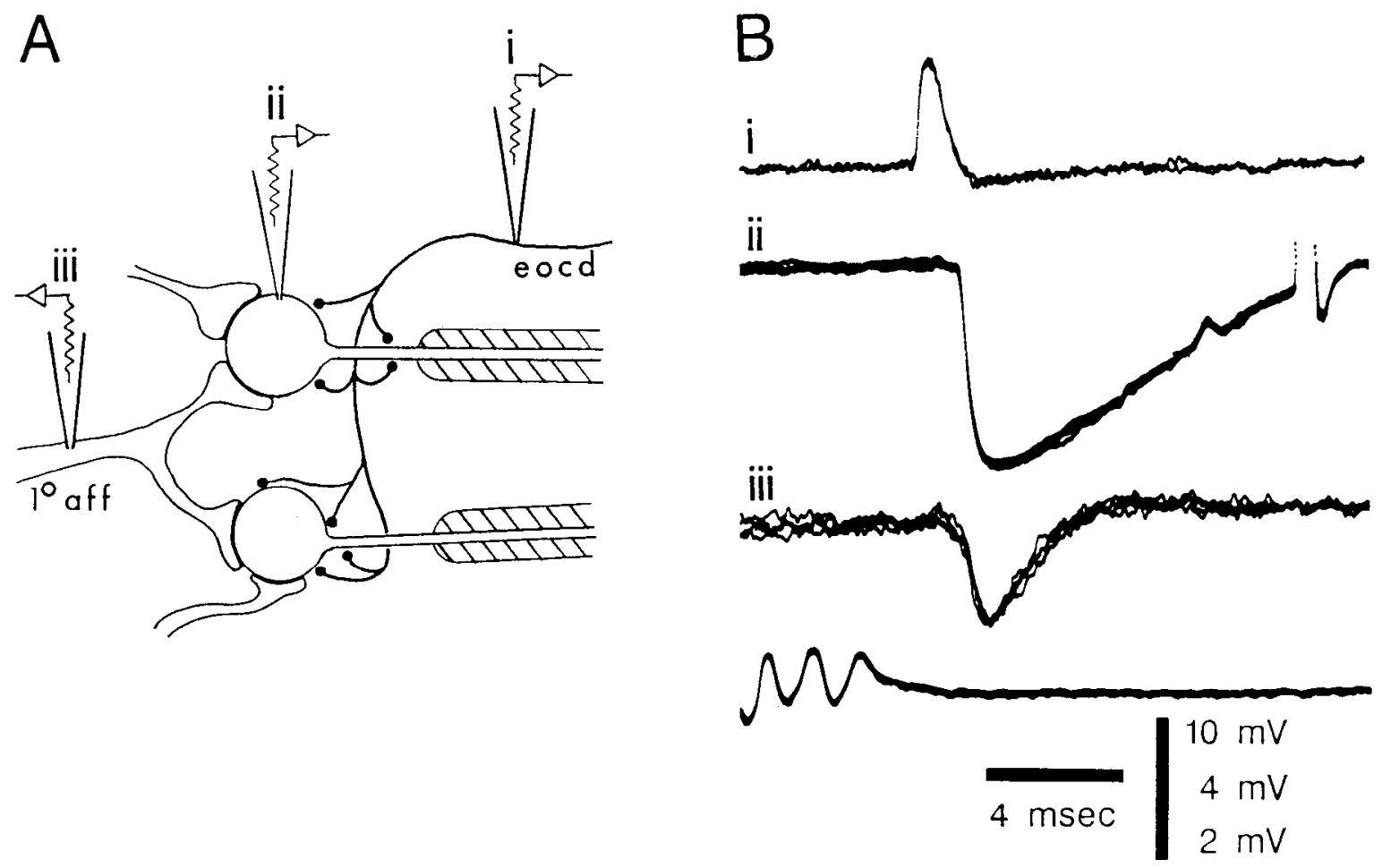

Figure 11. Fiber giving a single, corollary discharge driven spike and relative timing among 3 elements of NELL. $A$, Diagram showing recording sites for traces in $B$. B. Three different elements recorded in the same electrode track through NELL. Superimposed traces are shown for each recording. $i$, Fiber giving a single spike that is tightly coupled to the command signal. $i i$, NELL cell. The electrode was filled with KAc, so the ipsp of the cell did not invert. The effects of an electrosensory and an intracellular stimulus are visible at the right side of the trace. iii, Primary afferent. The ipsps in the cell and afferent begin about $1 \mathrm{msec}$ after the onset of the single spike in $i$. The corollary discharge ipsp in the afferent is of shorter duration than that in the cell.

ating zone of NELL cells may be at the distal end of the long initial segment where the myelin begins since this is the only location where they found a submembrane undercoat, a structure that is indicative of spike-generating membrane in other neurons (Peters et al., 1976). Our finding that the antidromic spikes in the afferents and in the cells were never more than a few millivolts in amplitude and were always smaller than the largest electrotonic epsp indicates that the antidromic impulses did not invade the soma even when the antidromic stimulus was maximal and excited many NELL axons simultaneously. The absence of somatic invasion was not due to injury caused by electrode penetration because the same absence was observed both in afferent and NELL cell recordings. The absence of somatic invasion by antidromic impulses and the apparent absence of orthodromically elicited somatic spikes suggests that the somas of NELL cells may be electrically inexcitable. Such electrical inexcitability, if present, would provide some functional advantages. Somatic inexcitability and the isolation of the spike-initiating zone at the end of a long, thin initial segment that is covered with inhibitory synapses would enhance the corollary discharge inhibition. Electrical inexcitability of the soma could also have the advantage of minimizing the unwanted spread of excitation to primary afferents or to other NELL cells via the gap junctions.

The finding that the ipsp in NELL cclls lastcd $10 \mathrm{mscc}$ or more, whereas the ipsp in the afferents lasted only 3-6 msec (Fig. $11 B$, ii, iii) was consistent and suggests the presence of a high-pass filter between the NELL cell and the fiber. High-pass filtering due to a capacitance in parallel with the resistance of a gap junction has not been described previously, although lowpass filtering between electrically coupled cells due to the capacitance of extrajunctional membrane has been described (Getting, 1974; Bennett, 1977). Capacitative coupling might be particularly prominent across the gap junctions between primary afferents and NELL cells because of the large contact area. A single afferent can have as many as 10 large (5-7 $\mu \mathrm{m}$ diameter) terminals on NELL cells, all of which are simultaneously hyperpolarized by the corollary discharge ipsp. Furthermore, lowpass filtering that could otherwise mask the high-pass filtering might be very small at this junction because of low extrajunctional capacitance due to the myelination of the presynaptic fibers. The brief durations and rapid rise times of the electrotonic epsps as recorded in the afferents are also more consistent with high- than with low-pass filtering. An alternative, though perhaps less likely, explanation for the difference in ipsp duration between cell and fiber would be the presence of a voltage-sensitive junctional resistance that is reduced by the hyperpolarization of the ipsp within a few milliseconds after its onset (K. Graubard, personal communication; Bennett and Spray, 1987).

The correlation in latency between the corollary discharge and electrosensory field potentials (Fig. 4) suggests a matching of the onset time of corollary discharge inhibition to the arrival time of peripheral input. Even a rough correspondence would be advantageous in optimally timing the corollary discharge inhibition so that it can be as brief as possible and still block the reafferent response evoked by the fish's own EOD.

The mechanism for the correspondence in latency could be quite simple. The fibers responsible for the inhibition descend 
from a sublemniscal nucleus rostral to ELL (Bell et al., 1981; Mugnaini and Maler, 1987b). The difference in central conduction time to the rostral and caudal NELL for these fine fibers may roughly match the difference in peripheral conduction time for the much larger primary knollenorgan afferents. The skin stimulus for the top recording in Figure $4 A$ was located $53 \mathrm{~mm}$ anterior to the skin stimulus for the bottom record, and the NELL recording site for the top records in Figure 4 was located $1.2 \mathrm{~mm}$ anterior to the recording site for the bottom records. If the central conduction time compensated exactly for the peripheral conduction time then the ratio of these 2 distances$1.2 / 53$, or 0.022 - would be an estimate of the ratio of conduction velocities in the 2 fiber types. The conduction velocity of knollenorgan afferents is about $40 \mathrm{~m} / \mathrm{sec}$ (Bennett, 1965), which means that the central conduction velocity would be about 0.9 $\mathrm{m} / \mathrm{sec}$.

Systematic variations in conduction velocity that accomplish an integrative purpose have been described in gymnotoid electric fish for the electric organ discharge control system (Bennett, 1971) and for the T type of electroreceptor afferents (Heiligenberg and Dye, 1982). One would also expect close control over conduction times in other systems where timing is critical, as in the measurement of interaural time delays or in echolocation.

A modifiable corollary discharge has been found in the ampullary receiving region of ELL, in which a change in the afferent input that follows the EOD motor command results in a corresponding change in the effect of the motor command alone (Bell, 1982). No modifiable corollary discharge effects were observed in NELL, however. Neither extensive pairing of a sensory input with the command signal nor extensive lack of pairing had any noticeable effect on the corollary discharge ipsp in NELL. There is probably little need for modifiability in the knollenorgan corollary dischargc; the knollenorgan response to the fish's own EOD is extremely stereotyped and largely invariant.

\section{Preservation of temporal information}

Behavioral studies of mormyrid fish have shown that they are capable of fine temporal discrimination in analyzing the EODs of other fish (Hopkins and Bass, 1981). In one species of mormyrid, for example, the EOD of the female is $0.4 \mathrm{msec}$ in duration, whereas the EOD of the male is $1.2 \mathrm{msec}$. Hopkins and Bass (1981) found that the males of this species usually respond to simple square waves of $0.4 \mathrm{msec}$ as if a female were present but respond much less or not at all to square waves of 0.1 or $1.6 \mathrm{msec}$. Such fine temporal discrimination requires that the temporal features of stimuli be accurately transmitted to the central nuclei responsible for analysis.

Other groups of animals also possess sensory subsystems that are specialized for the preservation and analysis of timing information. The $\mathrm{T}$ or phase coding system in the electrosensory system of gymnotoid electric fish (Szabo and Fessard, 1974; Heiligenberg, 1986) and the phase-sensitive component of the auditory system of the barn owl (Moiseff and Konishi, 1981; Takahashi et al., 1984) have been studied in particular detail. Carr (1986) has pointed out that these 2 systems share several morphological features that are probably related to the preservation of timing information. These features include large afferent fibers, minimal branching in the axonal arbor, large afferent terminals, and round adendritic or pauci-dendritic postsynaptic cells. Some of these features are also found in the part of the mammalian anteroventral cochlear nucleus that appears to be responsible for interaural phase comparisons (Smith and Rhode, 1987).

As described above, these features are also found in the mormyrid knollenorgan pathway between the peripheral receptor and the mesencephalon. In the periphery, the knollenorgan receptor cell generates a single all-or-none spike that shows very little shift in latency once threshold is crossed. The near absence of a dynamic range for this response indicates the insensitivity of the knollenorgan system to variations in stimulus intensity. The receptor cell spike in turn clicits a spike in the primary afferent via an electrical synapse (Bennett, 1965). Primary knollenorgan afferents are large and myelinated and conduct at 40 $\mathrm{m} / \mathrm{sec}$ (Szabo et al., 1979), near the maximum for a cold-blooded vertebrate. Within NELL, the afferents branch only a few times and generally remain both large and myelinated right up to their terminals (see Results; Szabo et al., 1983; Mugnaini and Maler, 1987b). The large terminals make electrical synapses onto the round adendritic cells of NELL. Some of these features continue to be present at the next level of the pathway. The axons of NELL that project to the mesencephalon conduct at $15 \mathrm{~m} / \mathrm{sec}$ (Szabo et al., 1979) and terminate with large electrical synapses on 2 types of cells, one of which is round and adendritic (Szabo et al., 1983; Mugnaini and Maler, 1987a).

Axons that are large and rapidly conducting up to their terminals have 3 features that are important with respect to transmission of temporal information. First, high-conduction velocity implies minimal variability in conduction time and, therefore, minimal temporal dispersion or temporal noise. Second, large fibers have shorter refractory periods than do small fibers (Paintal, 1966; Swadlow and Waxman, 1975), with the result that conduction time is minimally affected by a preceding impulse in the same axon. Third, the action potentials of large axons are of shorter duration than are those of small axons (Paintal, 1966), allowing shorter duration electrotonic epsps in the cells to which they are electrically coupled. It should also be noted that minimal branching in an axonal arbor, as observed with knollenorgan afferents, reduces the possibility of branch-point failure.

Similar considerations hold for the comparison of electrical and chemical synapses (Bennett, 1977). Thus, the brief synaptic delay of an electrotonic epsp will show little variability from impulse to impulse, and an electrotonic epsp will be minimally affected by an immediately preceding epsp at the same synapse, as was observed for the electrotonic epsps in NELL. Electrical synapses are a prominent feature of the timing pathways of mormyrid and gymnotoid electric fish (Maler et al., 1981; Szabo et al., 1983; Carr et al., 1986b; Mugnaini and Maler, 1987a, b) but do not appear to be present in the auditory timing pathways of birds and mammals (Jhaveri and Morest, 1982).

A round, adendritic cellular morphology also contributes to the preservation of timing information. Electrotonically introduced delays and slowing of rise times are reduced to a minimum in such cells, and all of the inputs have the maximal rise time possible. Rapid rise times mean that the time to threshold crossing for epsps is minimally affected by noise and, thus, is less variable.

The convergence of several afferent fibers onto the same NELL cell also enhances temporal performance since the summation of a set of synchronized inputs would result in a faster rise time in the postsynaptic cell than could be achieved by any single input. Similarly, temporal coupling between stimulus and neural response in the gymnotoid phase coding system is tighter at 
higher stages of processing, and convergence is considered the most likely explanation (Rose and Heiligenberg, 1985; Carr et al., 1986a).

In NELL at least, the enhancement of temporal performance by convergence brings with it a loss of spatial information. Thus, the finding that an impulse in any 1 of 2 or 3 afferents to a cell elicits a spike in that cell shows a loss of spatial information since such cells could not discriminate between electroreceptors at different skin locations. Poor preservation of spatial information by the knollenorgan system is also indicated by the large proportion of the nucleus that is included within the terminal field of single afferent fibers. The lack of morphological or physiological evidence for inhibitory surrounds is similarly consistent with poor preservation of spatial information. Inhibitory surrounds are usually present in systems in which spatial features of the stimulus are important.

In summary, the knollenorgan pathway up to the mesencephalon possesses several morphological and physiological specializations for ensuring the accurate preservation of temporal information about the stimulus. Intensity and spatial information is not well preserved by the knollenorgan system, however.

\section{References}

Alger, B. E. (1985) GABA and glycine: Postsynaptic actions. In Neurotransmitter Actions in the Vertebrate Nervous System, M. A. Rogawski and J. L. Barker, eds., pp. 33-68, Plenum, New York.

Bell, C. C. (1982) Properties of a modifiable efference copy in electric fish. J. Neurophysiol. 47: 1043-1056.

Bell, C. C. (1986) Electroreception in mormyrid fish, central physiology. In Electroreception, T. H. Bullock and W. Heiligenberg, eds., pp. 423-452, Wiley, New York.

Bell, C. C., and C. J. Russell (1976) Termination of tonic electroreceptors in lateral line lobe of mormyrids. Soc. Neurosci. Abstr. 2: 177.

Bell, C. C., and C. J. Russell (1978) Termination of electroreceptor and mechanical lateral line afferents in the mormyrid acousticolateral area. J. Comp. Neurol. 182: 367-382.

Bell, C. C., J. P. Myers, and C. J. Russell (1974) Electric organ discharge patterns during dominance-related behavioral displays in Gnathonemus petersii. J. Comp. Physiol. 92: 201-228.

Bell, C. C., T. E. Finger, and C. J. Russell (1981) Central connections of the posterior lateral line lobe in mormyrid fish. Exp. Brain Res. 42: 9-22.

Bennett, M. V. L. (1965) Electroreceptors in mormyrids. Cold Spring Harbor Symp. Quant. Biol. 30: 245-262.

Bennett, M. V. L. (1971) Electric organs. In Fish Physiology, W. S. Hoar and D. J. Randall, eds., pp. 347-491, Academic, New York.

Bennett, M. V. L. (1977) Electrical transmission: A functional analysis and comparison to chemical transmission. In Handbook of Physiology. Section I, Vol. 1. Cellular Biology of Neurons, Part I, J. M. Brookhart et al., eds., pp. 357-416, Am. Physiol. Soc., Bethesda, MD.

Bennett, M. V. L., and D. C. Spray (1987) Intracellular communication mediated by gap junctions can be controlled in many ways. In $S y n-$ aptic Function, G. M. Edelman, W. E. Gall, and W. M. Cowan, eds., pp. 109-135, Wiley, New York.

Bennett, M. V. L., and A. B. Steinbach (1969) Influence of electric organ control system on electrosensory afferent pathways in mormyrids. In Neurobiology of Cerebellar Evolution and Development, R. Llinás, ed., pp. 207-214, Am. Med. Assoc., Chicago.

Carr, C. E. (1986) Time coding in electric fish and barn owls. Brain Behav. Evol. 28: 122-133.

Carr, C. E., W. Heiligenberg, and G. J. Rose (1986a) A phase-comparison circuit in the electric fish midbrain. I: Behaviour and physiology. J. Neurosci. 6: 107-1 19.

Carr, C. E., L. Maler, and B. Taylor (1986b) A time-comparison circuit in the electric fish midbrain. II. Functional morphology. J. Neurosci. 6: $1372-1383$.

Denizot, J. P., S. Clausse, K. Elekes, M. Geffard, K. Grant, S. Libouban,
M. Ravaille-Veron, and T. Szabo (1987) Convergence of electrotonic club endings, GABA- and serotoninergic terminals on second order neurons of the electrosensory pathway in mormyrid fish, Gnathonemus petersii and Brienomyrus niger (Teleostei). Cell Tissue Res. 249: 301-309.

Enger, P. S., S. Libouban, and T. Szabo (1976a) Fast conducting electrosensory pathway in the mormyrid fish Gnathonemus petersii. Neurosci. Lett. 2: 133-136.

Enger, P. S., S. Libouban, and T. Szabo (1976b) Rhombo-mesencephalic connections in the fast conducting electrosensory system of the mormyrid fish, Gnathonemus petersii. An HRP study. Neurosci. Lett. 3: $239-243$.

Getting, P. (1974) Modification of neuron properties by electrotonic synapses. I. Input resistance, time constant and integration. J. Neurophysiol. 37: 846-857.

Heiligenberg, W. (1986) Jamming avoidance responses: Model systems for neuroethology. In Electroreception. T. H. Bullock and W. Heiligenberg, eds., pp. 613-650, Wiley, New York.

Heiligenberg, W., and J. Dye (1982) Labeling of electroreceptive afferents in a gymnotoid fish by intracellular injection of HRP: The mystery of multiple maps. J. Comp. Physiol. 148: 287-296.

Hopkins, C. D., and A. H. Bass (1981) Temporal coding of species recognition signals in an clectric fish. Sciencc 212: 85-87.

Jhaveri, S. R., and D. K. Morest (1982) Neuronal architecture in the nucleus magnocellularis of the chicken auditory system with observations on nucleus laminaris: A light and electron microscope study. Neuroscience 7: 809-835.

Kramer, B. (1974) Electric organ discharge interaction during interspecific agonistic behaviour in freely swimming mormyrid fish. A method to evaluate two or more. J. Comp. Physiol. 93: 203-236.

Kramer, B. (1979) Electric and motor responses of the weakly electric fish, Gnathonemus petersii (Mormyridae) to playback of social signals. Behav. Ecol. Sociobiol. 6: 67-69.

Maler, L., E. K. B. Sas, and J. Rogers (1981) The cytology of the posterior lateral line lobe of high frequency weakly electric fish (Gymnotidae): Dendritic differentiation and synaptic specificity in a simple cortex. J. Comp. Neurol. 195: 87-140.

Moiseff, A., and M. Konishi (1981) Neuronal and behavioural sensitivity to binaural time differences in the owl. J. Neurosci. 1: 40-48.

Mugnaini, E., and L. Maler (1987a) Cytology and immunohistochemistry of the nucleus exterolateralis anterior of the mormyrid brain: Possible role of GABAergic synapses in temporal analysis. Anat. Embryol. 176: 313-336.

Mugnaini, E., and L. Maler (1987b) Cytology and immunohistochemistry of the nucleus of the lateral line lobe in the electric fish $\mathrm{Gna}$ thonemus petersii (Mormyridae) brain. Evidence suggesting that GABAergic synapses mediate an inhibitory corollary discharge. Synapse I: $1-25$.

Paintal, A. S. (1966) The influence of diameter of medullated nerve fibres of cats on the rising and falling phases of the spike and its recovery. J. Physiol. (Lond.) 184: 791-811.

Peters, A., S. L. Palay, and H. Webster (1976) The Fine Structure of the Nervous System, Saunders, Philadelphia.

Rose, G., and W. Heiligenberg (1985) Temporal hyperacuity in the electric sense of fish. Nature 318: 178-180.

Russell, C. J., and C. C. Bell (1978) Neuronal responses to electrosensory input in the mormyrid valvula cerebelli. J. Neurophysiol. 41: 1495-1510.

Slesinger, P., and C. C. Bell (1985) Primary afferent fibers conduct impulses in both directions under physiological stimulus conditions. J. Comp. Physiol. 157: 15-22.

Smith, P. H., and W. S. Rhode (1987) Characterization of HRP labeled globular bushy cells in the cat anteroventral cochlear nucleus. J. Comp. Neurol. 266: 360-375.

Swadlow, H. A., and S. G. Waxman (1975) Variations in conduction velocity and excitability following single and multiple impulses of visual callosal axons in the rabbit. Exp. Neurol. 53: 128-150.

Szabo, T., and A. Fessard (1974) Physiology of electroreceptors. In Handbook of Sensory Physiology: Electroreceptors, Other Specialized Receptors in Other Vertebrates, A. Fessard, ed., p. 124, SpringerVerlag, Berlin.

Szabo, T., M. Ravaille, and S. Libouban (1978) Club endings of primary afferent fibres identified by anterograde horseradish peroxidase labeling: An EM study. Neurosci. Lett. 9: 7-15.

Szabo, T., P. S. Enger, and S. Libouban (1979) Electrosensory systems 
in the mormyrid fish, Gnathonemus petersii: Special emphasis on the fast conducting pathway. J. Physiol. (Paris) 75: 409-420.

Szabo, T., M. Ravaille, S. Libouban, and D. S. Enger (1983) The mormyrid rhombencephalon: I. Light and EM investigations on the structure and connections of the lateral line lobe nucleus with HRP labeling. Brain Res. 266: 1-19.
Takahashi, T., A. Moiseff, and M. Konishi (1984) Time and intensity cues are processed independently in the auditory system of the owl. J. Neurosci. 4: 1781-1786.

Zipser, B., and M. V. L. Bennett (1976) Interaction of electrosensory and electromotor signals in the lateral line lobe of a mormyrid fish. J. Neurophysiol. 39: 713-721. 